\title{
Effect of fluorine and nitrogen content on the properties of Ca-Mg-Si-Al-O- (N)-(F) glasses
}

\author{
Á. R. García-Bellés, C. Clausell*, A. Barba \\ Instituto Universitario de Tecnología Cerámica, Departamento de Ingeniería Química, Universitat Jaume I, \\ Castellón 12071, Spain \\ M. J. Pomeroy, S. Hampshire \\ Materials and Surface Science Institute, University of Limerick, Limerick, Ireland
}

\begin{abstract}
X-ray amorphous glasses of composition (in equivalent percent) 15Ca:15Mg: 55Si:15Al:(100-x-y)O: xN:yF with $\mathrm{x}=0,10,15$ and $\mathrm{y}=0,1,3,5$, were prepared by melting and casting. The effects of oxygen substitution by fluorine and/or nitrogen on the physical, mechanical, thermal and optical properties of the glasses have been investigated. Molar volume, fractional glass compactness, microhardness, Young's Modulus, glass-transition temperature, dilatometric-softening point and refractive index increased linearly with nitrogen substitution for oxygen, whereas molar volume and thermal expansion coefficient decreased linearly with nitrogen increase. In contrast, all properties except glass-transition temperature and dilatometric-softening point, are virtually unaffected by fluorine substitution for oxygen. Significant and linear, decreases in thermal properties occurred with increasing fluorine substitution level. All the data collected and its analysis clearly showed that the substitution effects of fluorine for oxygen on the studied properties of the glasses of the system with general formula Ca-Mg-Si-Al-O-(N)-(F) are totally independent and additive with respect to the substitution effects of nitrogen for oxygen on glass properties.
\end{abstract}

Keywords: oxynitride glasses, oxyfluoronitride glasses, fluorine, nitrogen 


\section{Introduction}

Oxynitride glasses are special types of silicate or aluminosilicate glasses in which the oxygen atoms of the glass network are partially replaced by nitrogen atoms. Numerous studies have focused on the formation and properties of oxynitride glasses in different systems ${ }^{1-10}$ showing that increases in glass transition temperature, hardness, elastic modulus, or viscosity, with regard to the corresponding oxide glasses, are due to a higher crosslink density provided by nitrogen within the glass network. In the case of fluorine-containing glasses, monovalent fluorine acts as a network terminator, thus reducing the connectivity of the glass network and causing a marked reduction in $\mathrm{T}_{\mathrm{g}}$ and viscosity as the fluorine content of the glasses is increased ${ }^{11,12}$.

These fluorine-containing glasses are used for a wide variety of purposes, among them bioglasses and bioglass ceramics, where fluoride release stimulates hydroxyapatite formation ${ }^{13}$ which bonds to human bone due to similar phase structure ${ }^{14-16}$. Fluorine is also introduced into ionomer glasses which are used for glass polyalkenoate dental cements, where fluorine atoms are added to lower the refractive index of the glass as well as to enable fluoride ion release from the set cement ${ }^{17}$ to prevent secondary $\operatorname{caries}^{18}$. Fluorine ions in human saliva and plasma also play an important role in development of hard tissues in the body ${ }^{19}$.

There is very little information available on oxyfluoronitride glasses and their properties. Vaughn and Risbud ${ }^{20}$ incorporated nitrogen into glasses in the $\mathrm{Zr}-\mathrm{Ba}-\mathrm{Al}-\mathrm{Y}-\mathrm{O}-\mathrm{F}$ system with the intention of increasing their thermal stability and improving their mechanical properties. What they actually observed was an increase in the glass transition temperature and crystallisation temperatures, as well as hardness. Later, Fletcher and Risbud ${ }^{21}$ used nitrogen to increase the stability and chemical durability of some fluorophosphate glasses in the $\mathrm{M}-\mathrm{Al}-\mathrm{P}-\mathrm{O}-\mathrm{F}-$ $\mathrm{N}$ system (where $\mathrm{M}=\mathrm{Ba}, \mathrm{Na}$ ). However, it was not until 20 years later that the first systematic studies were carried out in order to determine the combined effect of adding nitrogen and fluorine to aluminosilicate glasses ${ }^{22}$. The authors of this study explored the glass-forming region in the $\mathrm{Ca}-\mathrm{Si}-\mathrm{Al}-\mathrm{O}-\mathrm{N}-\mathrm{F}$ system and compared it with that obtained previously in the $\mathrm{Ca}-\mathrm{Si}-\mathrm{Al}-\mathrm{O}-\mathrm{N}$ system $^{23}$. The addition of fluorine, even in low quantities (1 eq\%), was shown to expand the glass-forming region, facilitating the dissolution of the modifier cations and nitrogen into the melt. The authors concluded that fluorine affects nitrogen dissolution into the melt, lowering the melting temperature and preventing the formation of crystalline phases. This study opened up the possibility of obtaining glasses with even higher nitrogen contents by using fluorine as a melting agent, harnessing the wellknown beneficial effects of nitrogen incorporation on the their physical and mechanical properties. 
In a previous study ${ }^{24}$, a systematic investigation was carried out of the effects of oxygen replacement by fluorine and nitrogen simultaneously on the physical (density, molar volume and compactness), thermal (glass-transition temperature, dilatometric-softening temperature and thermal expansion coefficient) and mechanical (Young's modulus and microhardness) properties of calcium-and calcium-yttrium-modified aluminosilicate glasses with a constant cation composition. In the previous work, an increase in fluorine substitution for oxygen was observed to produce an increase of thermal expansion coefficient, a decrease of glass-transition temperature and dilatometric-softening point and virtually no effect on molar volume, fractional glass compactness, Young's modulus and microhardness. Furthermore, increase in nitrogen substitution for oxygen was observed to produce an increase of glass fractional compactness, glass-transition temperature, dilatometric-softening point, Young's modulus and microhardness and a decrease of glass molar volume and thermal expansion coefficient. The results clearly showed that the effects of substitution of fluorine for oxygen and nitrogen for oxygen were independent and additive and that the effects on the property were very similar for the two different modifier compositions investigated.

This paper reports on an analogous study of calcium-magnesium aluminosilicate oxyfluoronitride glasses and how the modification of the fluorine and/or nitrogen substitution for oxygen affects their physical (density, molar volume and compactness), mechanical (microhardness, Young's modulus, shear modulus, compressive modulus and Poisson's rate), thermal (glass-transition temperature, dilatometric-softening point and thermal expansion coefficient) and optical (refraction index) properties.

\section{Experimental}

\section{(1) Design of glass composition}

For the formulation of the studied glasses, a preliminary study was carried out in order to find a suitable $\mathrm{Ca}: \mathrm{Mg}: \mathrm{Al}: \mathrm{Si}$ cation ratio which would allow a systematic study of the progressive substitution of oxygen by fluorine for different nitrogen contents. The initial chosen compositions are in the Mg-Si-Al-O-N system because its glass formation region is shorter than in the corresponding $\mathrm{Ca}-\mathrm{Si}-\mathrm{Al}-\mathrm{O}-\mathrm{N}$ system ${ }^{25}$ and, thereafter, partial substitution of $\mathrm{Mg}$ by $\mathrm{Ca}$ was undertaken without compromising the stability of the glasses. The chosen cation ratio corresponded to (in eq\%) 30Mg:55Si:15Al as being the one with the highest $\mathrm{Al}$ content with (in atomic ratios) $\mathrm{Al}: \mathrm{F}>1, \mathrm{Si}: \mathrm{Al}>1$ and $(\mathrm{Ca}+\mathrm{Mg}): \mathrm{Al}>0.5$, so $\mathrm{Al}$ atoms are expected to enter the glass network as $\left[\mathrm{AlO}_{4}\right]$ tetrahedra $^{22,26}$ leading to preferential formation of Al-F bonds over the undesirable Si-F bonds, which can lead to fluorine loss as volatile $\mathrm{SiF}_{4}$, or to formation of $\mathrm{Ca}-\mathrm{F}$ or $\mathrm{Mg}-\mathrm{F}$ bonds. 
The value of the partial Mg substitution by Ca (15Ca:15Mg:55Si:15Al in eq\%) was selected in order to be able to obtain similar fluorine and nitrogen substitution levels than the ones reached in previous work ${ }^{24}$. The nitrogen composition was modified between 0 and $15 \mathrm{eq} \%$ and the fluorine content between 0 and 5 eq\%. It was impossible to prepare glasses with higher nitrogen contents due to devitrification which occurred when these high nitrogen content compositions were formulated with also high contents of fluorine (5 eq\%).

The compositions of the twelve glasses in the Ca-Mg-Si-Al-O-(N)-(F) system used in this study are given in Table I.

\section{(2) Materials and methods}

Glass batches were prepared by wet ball milling the requisite amounts of $\mathrm{Si}_{3} \mathrm{~N}_{4}$ (UBE) and $\mathrm{CaF}_{2}$ (Aldrich) together with high purity $\left(99.9 \%\right.$ ) oxides ( $\mathrm{CaO}$ (Fisher), $\mathrm{MgO}$ and $\mathrm{SiO}_{2}$ (Fluka Chemika) and $\mathrm{Al}_{2} \mathrm{O}_{3}$ (Sumitomo)) for $4 \mathrm{~h}$, using $\mathrm{Al}_{2} \mathrm{O}_{3}$ milling media, a polyethylene container and isopropanol as the fluid. The mixtures were then dried by rotary evaporation. The dried powders were pressed into compacts by cold isostatic pressing at $150 \mathrm{MPa}$. These were then placed in a $\mathrm{BN}$-lined graphite crucible and fired at $1650^{\circ} \mathrm{C}$ in a vertical tube furnace under flowing nitrogen at $0.1 \mathrm{MPa}$ for $1 \mathrm{~h}$. The melt was then quickly withdrawn and poured into a preheated graphite mould to form glass bars followed by annealing at the respective glass-transition $\left(\mathrm{T}_{\mathrm{g}, \mathrm{DTA}}\right)$ temperature for $1 \mathrm{~h}$, to relieve cooling stresses, and then slow furnace-cooled to ambient temperature.

Specimens of each glass were cleaned and dried and then weighed dry and immersed in water to enable glassdensity determination by the Archimedes principle. Glass compactness (C) was calculated according to the expression:

$$
C=\frac{\sum_{1}^{i} x_{i} v_{i} N}{\sum_{1}^{i} x_{i} m_{i}} \cdot \rho
$$

where $x_{i}$ is the fraction of ionic species " $i$ ", $v_{i}$ the volume of ionic species and $m_{i}$ the ionic mass of the species; $N$ is Avogadro's number and $\rho$ the glass density. The value of $v_{i}$ was calculated using the ionic radii given by Shannon ${ }^{27}$ and the expression:

$$
v_{i}=\frac{4}{3} \pi \cdot r_{i}^{3}
$$

The molar volumes (MV) of the glasses were calculated according to the expression: 


$$
M V=\frac{\sum_{1}^{i} x_{i} m_{i}}{\rho}
$$

Specimens of each glass, $10 \mathrm{~mm} \times 3 \mathrm{~mm} \times 3 \mathrm{~mm}$ in size, were cut from the cast bars and placed in a dilatometer, Netzsch Dil 402-C. The specimens were then heated under flowing nitrogen, at a rate of $5^{\circ} \mathrm{C} / \mathrm{min}$, to above the dilatometric-softening point $\left(\mathrm{T}_{\mathrm{DS}}\right)$. The inflection point of the expansion curve was taken as the glass-transition temperature $\left(T_{g, \text { dil }}\right)$ while the maximum was taken as the $T_{D S}$. The thermal expansion coefficient $\left(\alpha_{300-600}\right)$ was calculated between 300 and $600^{\circ} \mathrm{C}$ using the following equation:

$$
\alpha_{T_{1}-T_{2}}=\frac{\Delta l / l_{0}}{\Delta T}
$$

where $l_{0}$ is the original length, $\Delta l$ is the change in length of the specimen and $\Delta T$ is the temperature change. From equation (4) $\alpha_{T_{1}-T_{2}}$ is defined in $\left({ }^{\circ} \mathrm{C}^{-1}\right)$.

Dilatometry curves for each glass were examined to ensure that there was no decrease in the $\Delta l / l_{0}$-temperature slope before the rapid increase in gradient above $T_{g, \text { dil. }}$. Any such decrease in slope would have reflected incomplete glass annealing and, consequently, any glass showing such behaviour should be re-annealed for an additional hour.

Differential thermal analysis was carried out using a Stanton-Redcroft STA 1640 instrument. $50 \mathrm{mg}$ of the glass powder were heated at $10^{\circ} \mathrm{C} / \mathrm{min}$ under $0.1 \mathrm{MPa}$ nitrogen atmosphere. The glass transition temperature $\left(\mathrm{T}_{\mathrm{g}, \mathrm{DTA}}\right)$ is represented by the point of inflection of the endothermic peak.

Specimens of the glass were mounted in a cold setting resin, polished to a $1 \mu \mathrm{m}$ finish and then subjected to microhardness testing (Leco microhardness tester) using a Vickers indenter with a $300 \mathrm{~g}$ load for $10 \mathrm{~s}$. Young's modulus (E) was measured using the ultrasonic pulse-echo-overlap technique and the expression:

$$
E=\rho \cdot \frac{3 \cdot V_{l}^{2}-4 \cdot V_{t}^{2}}{\frac{V_{l}^{2}}{V_{t}^{2}}-1}
$$

where $V_{l}$ and $V_{t}$ are the longitudinal and transverse ultrasonic wave velocities, respectively. Samples of $15 \mathrm{~mm} \mathrm{x}$ $10 \mathrm{~mm} \times 3 \mathrm{~mm}$ in size with parallel surfaces were used for the measurements.

Shear modulus $(G)$, compressive modulus $(B)$ and Poisson's ratio $(v)$ were determined using the following expressions: 


$$
\begin{aligned}
& G=\rho \cdot V_{t}^{2} \\
& B=\frac{E \cdot G}{3 \cdot(3 \cdot G-E)} \\
& v=\frac{E}{2 \cdot G}-1
\end{aligned}
$$

Finally, refractive index was measured using an Ellipsometer (J. A. Woollam and Co. Inc.). Values taken were for $500 \mathrm{~nm}$ (visible spectrum) using a glass slide polished to $1 \mu \mathrm{m}$.

\section{Results and discussion}

As expected, all glasses were X-ray amorphous and fully dense, that is, they contained no internal bubbles or pores. However, some of them were not completely homogeneous, displaying different colour shades with some exhibiting a grey-blue hue. Only the glasses with higher nitrogen content (15 eq\%) are not transparent to light (1.5 mm thickness).

\section{(1) Effects of fluorine and nitrogen on physical properties}

The physical properties (density, molar volume and fractional compactness) of the Ca-Mg-Si-Al-O-(N)-(F) glasses are also given in Table I and, the last two, are represented in Figures 1 and 2, respectively, against fluorine and nitrogen contents (discrete values). As can be observed, oxygen substitution by fluorine has no significant effect on molar volume or fractional compactness, even though this last property seems to increase very slightly. This is in contrast to the introduction of nitrogen into the glass network, which results in a linear increase of fractional compactness, and the resulting reduction, also linear, of the molar volume.

In silicate glasses, the network comprises $\mathrm{SiO}_{4} \mathrm{~N}$ tetrahedra bridged by bi-coordinate O-T linkages whereas, in oxynitride glasses, it is known from the literature ${ }^{1,4,9,28}$ that the network comprises $\mathrm{SiO}_{(4-\mathrm{x})} \mathrm{N}_{\mathrm{x}}$ tetrahedra, with average $\mathrm{x}$ values controlled by $\mathrm{N}: \mathrm{Si}$ ratios, which are bridged either by bi-coordinate $\mathrm{O}-\mathrm{T}$ linkages or tricoordinate N-T linkages. Thus nitrogen increases the crosslinking of the glass network. $\mathrm{AlO}_{4}$ tetrahedra are present and are mainly bridged by bi-coordinate O-T linkages. Each eq.\% nitrogen substitution introduces the same number of additional crosslinks into the glass network. The extent of network crosslinking will increase linearly with eq. $\% \mathrm{~N}$ which will have the result of contracting the glass network, thus increasing glass compactness and decreasing molar volume in a linear manner. 
This improvement of the physical properties with nitrogen content is consistent with other earlier studies of oxynitride glasses found in the literature $6,7,9,23,28-32$. However, if the oxyfluoronitride glasses results are compared with those obtained for oxyfluoride glasses, a significant decrease in molar volume with the nitrogen content is observed, which confirms the cross-linking role of the nitrogen in the glass network, even in the presence of a strong modifying ion such as fluorine.

In view of the above results, and taking into account the linearity of the composition-properties relationship, a linear least-square fit of the experimental data has been performed. The results of the fitting are shown in Table IV and in Figures 1 and 2 as solid lines. As can be observed, reasonably linear correlations with similar gradients were observed with respect to the effect of fluorine and nitrogen substitution levels on properties $\left(\mathrm{R}^{2}\right.$ values close to 0.99 and error band values similar to the ones experimentally obtained).

The results given in Table IV allow calculation of the effect of fluorine and nitrogen contents on any of the studied properties. In this way, for example, molar volume can be expressed as follows:

$$
M V=7.57-0.0085 \cdot[\mathrm{N}]+0.0032 \cdot[\mathrm{F}] \quad\left(\mathrm{cm}^{3} / \mathrm{mol}\right)
$$

where $[\mathrm{N}]$ and $[\mathrm{F}]$ are the nitrogen and fluorine concentrations in eq\%, respectively. So, for a 15 eq\% of nitrogen and $5 \mathrm{eq} \%$ of fluorine, the estimated value of the molar volume is $7.46 \mathrm{~cm}^{3} / \mathrm{mol}$, which is exactly the same value of the one experimentally obtained (see Table I). The good correlation between the experimental data and the calculated values is evidence of the fact that the effects of oxygen replacement by fluorine (for fixed nitrogen content) and oxygen replacement by nitrogen (for fixed fluorine content) on physical properties are independent and additive, rather than synergistic.

The results obtained are quite similar to those for the $\mathrm{Ca}-\mathrm{Si}-\mathrm{Al}-\mathrm{O}-(\mathrm{N})-(\mathrm{F})$ system previously reported ${ }^{24}$. In fact, the data are slightly lower for nitrogen and almost identical for fluorine. A lower error band value has been obtained for these physical properties and the values of the composition-property gradient for both glass systems are all of the same order of magnitude, consistent with the previously published results while expanding the range of compositions into this new system with mixed modifiers and with a significantly different cation ratio.

\section{(2) Effects of fluorine and nitrogen on mechanical properties}

The mechanical properties (microhardness, Young's modulus, shear modulus, compressive modulus and Poisson's ratio) of the Ca-Mg-Si-Al-O-(N)-(F) glasses are shown in Table II. 
As can be observed, oxygen replacement by fluorine has a negligible effect on the mechanical properties, while oxygen replacement by nitrogen results in a significant linear increase of these properties, without any data deviation from the general tendency. Also the present results are consistent with other data on oxynitride glasses from the literature $6,7,23,28,30,31,33-35$.

Fig. 3 shows the effect of fractional compactness and free volume (discrete values) on microhardness and Young's modulus. The results highlight how both mechanical properties are related to the network connectivity of the glass. Compactness is unaffected by oxygen substitution by fluorine and this property is controlled by free volume, defined as molar volume less the volume occupied by ions ${ }^{36}$. Thus, as can be seen in Fig. 4, fluorine substitution level has no appreciable effect on free volume, whereas, nitrogen substitution results in a significant decrease of this parameter, following a linear tendency.

The change in free volume with fluorine substitution $\left(+0.0005 \mathrm{~cm}^{3} / \mathrm{mol} \cdot(\mathrm{eq} \% \mathrm{~F})^{-1}\right)$ is clearly negligible compared with the change with nitrogen substitution $\left(-0.0094 \mathrm{~cm}^{3} / \mathrm{mol} \cdot(\mathrm{eq} \% \mathrm{~N})^{-1}\right)$, although this change is lower than observed in other related glass systems ${ }^{24}:\left(-0.0143 \mathrm{~cm}^{3} / \mathrm{mol} \cdot(\mathrm{eq} \% \mathrm{~N})^{-1}\right.$ for the $\mathrm{Ca}-\mathrm{Si}-\mathrm{Al}-\mathrm{O}-(\mathrm{N})-(\mathrm{F})$ system and $-0.0146 \mathrm{~cm}^{3} / \mathrm{mol} \cdot(\mathrm{eq} \% \mathrm{~N})^{-1}$ for the $\mathrm{Ca}-\mathrm{Y}-\mathrm{Si}-\mathrm{Al}-\mathrm{O}-(\mathrm{N})-(\mathrm{F})$ system $)$.Fig. 4 suggests that there is a slight increase of the free volume with the incorporated fluorine at 0 and $10 \mathrm{eq} \% \mathrm{~N}$ and this is in agreement with previous results found in the literature ${ }^{34}$.

A linear least-square fit of the experimental data allows an empirical formula to be obtained which relates each of the mechanical properties with the content of nitrogen or fluorine (see Table IV). In this way, for example, Young's modulus can be expressed as:

$$
E=102.80+0.795 \cdot[\mathrm{N}]+0.073 \cdot[\mathrm{F}] \quad(\mathrm{GPa})
$$

where $[\mathrm{N}]$ and $[\mathrm{F}]$ are the nitrogen and fluorine concentrations in eq\%, respectively. So, using the relationship, for a glass containing $15 \mathrm{eq} \%$ nitrogen and $5 \mathrm{eq} \%$ fluorine, the estimated value of the Young's modulus is 115.1 $\mathrm{GPa}$, and the experimental value, as can be seen in Table II, is $116.1 \mathrm{GPa}$. The good correlation between the experimental data and the calculated values is further evidence that the effects of nitrogen and fluorine substitution on glass mechanical properties are independent and additive rather than synergistic.

The changes in properties with nitrogen substitution for oxygen, as shown by the gradients in Table IV, as with the physical properties discussed above, are very similar to those for the $\mathrm{Ca}-\mathrm{Si}-\mathrm{Al}-\mathrm{O}-(\mathrm{N})-(\mathrm{F})$ system previously reported ${ }^{24}$. However, for the changes in properties with fluorine substitution, the present calculated gradients are significantly lower than determined previously. 
The thermal properties of the glasses are shown in Table III: thermal expansion coefficient, glass-transition temperature, $\mathrm{Tg}$ (measured by DTA: $\mathrm{Tg}_{\mathrm{DTA}}$ and dilatometry: $\mathrm{Tg}_{\mathrm{dil}}$ ), and dilatometric softening point, $\mathrm{T}_{\mathrm{DS}}$. Figures 5,6 and 7, respectively, show the changes of $\operatorname{Tg}_{\mathrm{DTA}}, \mathrm{T}_{\mathrm{DS}}$ and thermal expansion coefficient $(\alpha)$ with fluorine and nitrogen substitutions.

The obtained data confirms the trends observed in previous studies of similar oxynitride glass systems ${ }^{24}$. The bridging oxygen substitution by non-bridging terminating fluorine reduces the network connectivity, explaining the reductions in $T_{g, D T A}$ and $T_{D S}$. On the other hand, as nitrogen substitutes for oxygen, it becomes chemically bonded to silicon in the glass network and produces a more tightly packed and highly linked structure, which explains the increase of these thermal properties.

The changes in $\mathrm{Tg}_{\mathrm{DTA}}$ and $\mathrm{T}_{\mathrm{DS}}$ with fluorine and nitrogen substitution are clearly linear. However, for the thermal expansion coefficient, there is no clear relationship, although it seems that the general trend is that $\alpha_{300-600}$ increases with fluorine substitution and decreases with nitrogen content as also observed previously ${ }^{4}$.

As with the physical and mechanical properties, Table IV includes the values of the linear least-squares fit slopes of the thermal properties with variation in fluorine and nitrogen contents, which are also represented, together with the experimental data, in Figures 5, 6 and 7. These fits allow empirical formulae to be obtained that relate each of the thermal properties with the contents of nitrogen and fluorine. For example, dilatometric softening point can be expressed as follows:

$$
T_{D S}=691.6+3.12 \cdot[\mathrm{N}]-16.68 \cdot[\mathrm{F}] \quad\left({ }^{\circ} \mathrm{C}\right)
$$

where $[\mathrm{N}]$ and $[\mathrm{F}]$ are, respectively, the nitrogen and fluorine concentrations in eq\%. So, for a glass containing $15 \mathrm{eq} \%$ nitrogen and $5 \mathrm{eq} \%$ fluorine, the estimated value of the $\mathrm{T}_{\mathrm{DS}}$ is $655^{\circ} \mathrm{C}$, and the experimental value, as can be seen in Table III, is $658^{\circ} \mathrm{C}$, which is within experimental error. The goodness of fit $\left(\mathrm{R}^{2}\right)$ and the close agreement between calculated and measured property values clearly shows again that nitrogen and fluorine substitutions have independent but additive effects on the properties of the $\mathrm{Ca}-\mathrm{Mg}-\mathrm{Si}-\mathrm{Al}$-oxyfluoronitride glasses studied here.

Comparing with the $\mathrm{Ca}-\mathrm{Si}-\mathrm{Al}-\mathrm{O}-(\mathrm{N})-(\mathrm{F})$ system previously studied ${ }^{24}$, the effect of nitrogen on the thermal properties is slightly higher for the present mixed modifier $\mathrm{Ca}-\mathrm{Mg}-\mathrm{Si}-\mathrm{Al}-\mathrm{O}-(\mathrm{N})-(\mathrm{F})$ system, but is always in the same range as the results obtained for oxynitride glasses in the literature (between 2.6 and $4.1^{\circ} \mathrm{C} / \mathrm{eq} \% \mathrm{~N}$ for 
$\mathrm{T}_{\mathrm{g}, \mathrm{DTA}}$ and between 2.3 and $3.8^{\circ} \mathrm{C} / \mathrm{eq} \% \mathrm{~N}$ for $\mathrm{T}_{\mathrm{DS}}$ found for other oxynitride glasses ${ }^{37}$, and $2.3{ }^{\circ} \mathrm{C} / \mathrm{eq} \% \mathrm{~N}$ for $\mathrm{T}_{\mathrm{g}, \mathrm{DTA}}$ found for other oxyfluoronitride glasses $^{34}$ ).

By contrast, the fluorine effect is remarkably lower in the system with mixed modifiers, even though these values are consistent with the ones previously reported for oxyfluoride glasses ${ }^{34,38,39}\left(-14.1^{\circ} \mathrm{C} / \mathrm{eq} \% \mathrm{~F}\right.$ or between $-7.7^{\circ} \mathrm{C} / \mathrm{eq} \% \mathrm{~F}$ and $\left.-13.1^{\circ} \mathrm{C} / \mathrm{eq} \% \mathrm{~F}\right)$ and for oxyfluoronitride glasses ${ }^{34}\left(-20.8^{\circ} \mathrm{C} / \mathrm{eq} \% \mathrm{~F}\right.$ for $\left.\mathrm{T}_{\mathrm{g}, \mathrm{DTA}}\right)$.

However, it is important to note that the cation ratios used in the present $\mathrm{Ca}-\mathrm{Mg}-\mathrm{Si}-\mathrm{Al}-\mathrm{O}-(\mathrm{N})-(\mathrm{F})$ systemand the previously studied $\mathrm{Ca}-\mathrm{Si}-\mathrm{Al}-\mathrm{O}-(\mathrm{N})-(\mathrm{F})$ system ${ }^{24}$ are different, which also means that the $(\mathrm{Ca}+\mathrm{Mg}): \mathrm{Al}$ and $\mathrm{Al}: \mathrm{F}$ ratios will be different. In fact, in the $\mathrm{Ca}$ modified glasses, $\mathrm{Ca}: \mathrm{Al}=1$ and $\mathrm{Al}: \mathrm{F} \geq 1.43$, whereas in the mixed $\mathrm{Ca}-\mathrm{Mg}$ modified glasses, $\mathrm{Ca}: \mathrm{Al}=3$ and $\mathrm{Al}: \mathrm{F} \geq 1$. Even though both systems have the minimum established ratios to keep $\mathrm{Al}$ in tetrahedral coordination, the $\mathrm{Al}$ available for bonding with $\mathrm{F}$ is lower in the mixed modifier glasses. Thus, F should link with $\mathrm{Ca}$ or $\mathrm{Mg}$, disturbing the cohesive capability of the modifier cations (less effective charges to link non-bridging oxygens), but resulting in a network disrupting effect additional to the fluorine incorporation into the network itself.

\section{(4) Effects of fluorine and nitrogen on refractive index}

Values for refractive index as a function of fluorine and nitrogen content of the glasses are given in Table III and Fig. 8 in which the discrete points represent the experimental data and the lines correspond to the best fit of the data.

Refractive index increases linearly with nitrogen, and shows a slight decrease with fluorine, these effects being consistent with data in the literature ${ }^{11,25,40}$ and with the polarizability of oxygen, nitrogen and fluorine ions.

The refractive index of glasses depends both on density and electronic structure of each of its ions, as is well established by the Lorenz-Lorenz relation:

$$
R_{m}=\left(\frac{M}{\rho}\right) \cdot\left(\frac{n^{2}-1}{n^{2}+2}\right)
$$

where $R_{m}$ is the molar refractivity, $M$ is the molecular weight, $\rho$ is the density and $n$ is the refractive index. Equation (12) can be rearranged as follows:

$$
n=\left[\frac{2 \cdot R_{m} \cdot \rho+M}{M-\rho \cdot R_{m}}\right]^{\frac{1}{2}}
$$


So, the refractive index varies with molar refractivity, which in turn depends on polarizability of the ions in the glass, its density and molecular weight, which depend on chemical composition. Since the cation composition of the glasses is constant, the value of refractive index will only depend on the fluorine and nitrogen contents of the glass. According to Coon and Goyle ${ }^{41}$, the ionic refraction (which is proportional to ion polarizability) is 66.6 for nitrogen, but only 13.3 for oxygen, which explains the increase in refractive index when oxygen is substituted by nitrogen. Moreover, nitrogen substitution for oxygen in the glass network increases density, thus allowing an increase in this optical property. In contrast, the polarizability of the oxygen ion is three times higher than that of the fluorine ion ${ }^{42}$, which explains the decrease in refractive index with fluorine substitution, since both density and molecular mass remain almost constant.

\section{Conclusions}

In the present study, the effects of oxygen substitution by fluorine and/or nitrogen on various physical, mechanical, thermal and optical properties in a series of $\mathrm{Ca}-\mathrm{Mg}-\mathrm{Si}-\mathrm{Al}-$ oxyfluoronitride glasses of composition (in equivalent percent): 15Ca:15Mg:55Si:15Al:(100-x-y)O:xN:yF with $\mathrm{x}=0,10,15$ and $\mathrm{y}=0,1,3,5$, have been analysed and lead to the following conclusions:

1. Oxygen substitution by fluorine has no significant effect on the molar volume, fractional compactness, Young's modulus and microhardness of the glass, independent of its nitrogen content.

2. Oxygen substitution by nitrogen reduces the molar volume of the glass and linearly increases its fractional compactness, Young's modulus and microhardness, independent of its fluorine content.

3. The effects of fluorine and/or nitrogen substitution on the mechanical properties (Young's modulus and microhardness) can be explained in terms of changes in values of glass compactness. Substitution of nitrogen for oxygen in the glass results in a linear increase of fractional compactness and a reduction of the molar volume, both of these effects indicating that nitrogen increases the crosslinking of the glass network. The network disruption caused by substitution of fluorine does not significantly affect the glass compactness and, hence, the mechanical properties.

4. Substituting oxygen by fluorine, at any nitrogen content, reduces the glass-transition temperature and the dilatometric softening point by approximately $16{ }^{\circ} \mathrm{C} / \mathrm{eq} \% \mathrm{~F}$, since the introduction of fluorine causes the 
disruption of the glass network, due to the presence of Al-F terminations and additional non-bridging oxygens.

5. Substituting oxygen by nitrogen, at any fluorine content, increases the glass-transition temperature and the dilatometric softening point by approximately $3{ }^{\circ} \mathrm{C} / \mathrm{eq} \% \mathrm{~N}$, since nitrogen introduction brings extra connectivity to the glass network.

6. The refractive index of the glasses increases linearly with nitrogen substitution and decreases slightly with fluorine substitution. These changes are due to the differences in the polarizability of oxygen, nitrogen and fluorine ions.

7. The data presented show that the effects of oxygen replacement by fluorine (for fixed nitrogen content) and oxygen replacement by nitrogen (for fixed fluorine content) on physical, mechanical, thermal and optical properties of these oxyfluoronitride glasses are independent and additive, rather than synergistic.

\section{Acknowledgment}

The authors wish to acknowledge Science Foundation Ireland and Valencian Institutions for financial support of this research and to thank colleagues in the Materials and Surface Science Institute for their help and advice.

\section{References}

$1 \quad$ S. Hampshire, “Oxynitride glasses,” J. Eur. Ceram. Soc., 28 [7] 1475-1483 (2008).

2 R.E. Loehman, "Preparation and properties of oxynitride glasses," J. Non. Cryst. Solids, 56 [1-3] 123134 (1983).

3 P.F. Becher, S.B. Waters, C.G. Westmoreland, and L. Riester, "Compositional Effects on the Properties of Si-Al-RE-Based Oxynitride Glasses (RE = La, Nd, Gd, Y, or Lu),” J. Am. Ceram. Soc., 85 [4] 897902 (2004).

4 P.F. Becher, S. Hampshire, M.J. Pomeroy, M.J. Hoffmann, M.J. Lance, and R.L. Satet, “An Overview of the Structure and Properties of Silicon-Based Oxynitride Glasses,” Int. J. Appl. Glas. Sci., 2 [1] 63-83 (2011).

$5 \quad$ K.R. Shillito, R.R. Wills, and R.B. Bennett, "Silicon metal oxynitride glasses," J. Am. Ceram. Soc., 61 [11-1] $537(1978)$ 
R.A.L. Drew, S. Hampshire, and K.H. Jack, "Nitrogen Glasses;” pp. 119-132 in Spec. Ceram. 7, Vol. 31. Edited by P. Popper. Brit. Ceram.Proc., Stokeon-Trent, UK, 1981.

S. Hampshire, E. Nestor, R. Flynn, J.L. Besson, T. Rouxel, H. Lemercier, P. Goursat, M. Sebai, et al., "Yttrium oxynitride glasses: Properties and potential for crystallisation to glass-ceramics," J. Eur. Ceram. Soc., 14 [3] 261-273 (1994).

Z. Lian, S. Wang, L. Tian, and W. Ge, "Preparation and Properties of Alkaline-earth Silicon Oxynitride Glasses;" pp. 819-822 in Appl. Eng. Mater. PTS 1-4. Edited by Bu, JL and Wang, PC and Ai, L and Sang, XM and Li, YG. TRANS TECH PUBLICATIONS LTD, LAUBLSRUTISTR 24, CH-8717 STAFA-ZURICH, SWITZERLAND, 2011.

E. Dolekcekic, M.J. Pomeroy, and S. Hampshire, "Structural characterisation of Er-Si-Al-O-N glasses by Raman spectroscopy," J. Eur. Ceram. Soc., 27 [2] 893-898 (2007).

S. Ali and B. Jonson, "Compositional effects on the properties of high nitrogen content alkaline-earth silicon oxynitride glasses, AE=Mg, Ca, Sr, Ba,” J. Eur. Ceram. Soc., 31 [4] 611-618 (2011).

E. De Barra and R.G. Hill, "Influence of glass composition on the properties of glass polyalkenoate cements. Part III: influence of fluorite content," Biomaterials, 21 [6] 563-569 (2000).

L. Lin, G. Ren, M. Chen, Y. Liu, and Q. Yang, "Study of fluorine losses and spectroscopic properties of Er3+ doped oxyfluoride silicate glasses and glass ceramics," Opt. Mater. (Amst)., 31 [10] 1439-1442 (2009).

K.T. Stanton and R.G. Hill, "Crystallisation in apatite-mullite glass-ceramics as a function of fluorine content," J. Cryst. Growth, 275 [1] e2061-e2068 (2005).

K.T. Stanton, K.P. O’Flynn, S. Kiernan, J. Menuge, and R.G. Hill, "Spherulitic crystallization of apatitemullite glass-ceramics: Mechanisms of formation and implications for fracture properties," J. Non. Cryst. Solids, 356 [35] 1802-1813 (2010).

A. Rafferty, A. Clifford, R.G. Hill, D. Wood, and M. Dimitrova-lukacs, "Influence of Fluorine Content in Apatite - Mullite Glass-Ceramics," Am. Ceram. Soc., 83 [11] 2833-2838 (2000).

X. Chatzistavrou, O. Tsigkou, H.D. Amin, K.M. Paraskevopoulos, V. Salih, and A.R. Boccaccini, "Solgel based fabrication and characterization of new bioactive glass-ceramic composites for dental applications,” J. Eur. Ceram. Soc., 32 [12] 3051-3061 (2012). 
R.. Billington, J.. Williams, A. Dorban, and G.. Pearson, "Glass ionomer cement: evidence pointing to fluorine release in the form of monofluorophosphate in addition to fluoride ion," Biomaterials, 25 [17] 3399-3402 (2004).

H.H.K. Xu, J.L. Moreau, L. Sun, and L.C. Chow, "Strength and fluoride release characteristics of a calcium fluoride based dental nanocomposite," Biomaterials, 29 [32] 4261-4267 (2008).

J. Wei, J. Wang, X. Liu, J. Ma, C. Liu, J. Fang, and S. Wei, "Preparation of fluoride substituted apatite cements as the building blocks for tooth enamel restoration,” Appl. Surf. Sci., 257 [17] 7887-7892 (2011)

W.L. Vaughn and S.H. Risbud, "New Fluoronitride Glasses in Zirconium-Metal-F-N Systems," $J$. Mater. Sci. Lett., 3 [2] 162-164 (1984).

J.P. Fletcher and S.H. Risbud, "Preparation of oxyfluoronitride glasses from fluorophosphate-AlN melts," Mater. Lett., 6 145-148 (1988).

A.R. Hanifi, M.J. Pomeroy, and S. Hampshire, "Novel Glass Formation in the Ca-Si-Al-O-N-F System," J. Am. Ceram. Soc., 94 [2] 455-461 (2011).

S. Hampshire, R.A.L. Drew, and K.H. Jack, “Oxynitride Glasses,” Phys. Chem. Glas., 26 [5] 182-186 (1985)

Á.R. García-Bellés, M. Monzó, A. Barba, C. Clausell, M.J. Pomeroy, A.R. Hanifi, and S. Hampshire, "Properties of Ca-(Y)-Si-Al-O-N-F Glasses: Independent and Additive Effects of Fluorine and Nitrogen,” J. Am. Ceram. Soc., 96 [4] 1131-1137 (2013).

R.A.L. Drew, Nitrogen glass. Research reports in Materials Science. The Parthenon Press, England, 1986.

R.G. Hill, C. Goat, and D. Wood, "Thermal-analysis of a SiO2-A2O3-CaO-CaF2 glass,” J. Am. Ceram. Soc., 75 [4] 778-785 (1992).

R.D. Shannon, "Revised effective ionic radii and systematic studies of interatomic distances in halides and chalcogenides," Acta Crystallogr. Sect. A, 32 [5] 751-767 (1976).

M.J. Pomeroy, and S. Hampshire, "SiAlON Glasses: Effects of Nitrogen on Structure and Properties;" J. Ceram. Soc. Jap., 116 [6] 755-761 (2008). 
R.K. Brow and C.G. Pantano, "Thermochemical nitridation of microporous silica films in ammonia," $J$. Am. Ceram. Soc., 70 [1] 9-14 (1987).

R. Ramesh, E. Nestor, M.J. Pomeroy, and S. Hampshire, "Formation of Ln-Si-Al-O-N glasses and their properties," J. Eur. Ceram. Soc., 17 [15-16] 1933-1939 (1997).

M.J. Pomeroy and S. Hampshire, "Composition - structure - property relationships for Si-Al-O-N glasses containing mixed modifiers," Ann. Chim., 28 [2] 63-70 (2003).

M.J. Pomeroy, E. Nestor, R. Ramesh, and S. Hampshire, "Properties and crystallization of rare-earth SiAl-O-N glasses containing mixed trivalent modifiers," J. Am. Ceram. Soc., 88 [4] 875-881 (2005).

A.R. Hanifi, A. Genson, M.J. Pomeroy, and S. Hampshire, “Oxyfluoronitride glasses with high elastic modulus and low glass transition temperatures," J. Am. Ceram. Soc., 92 [5] 1141-1144 (2009).

A.R. Hanifi, A. Genson, M.J. Pomeroy, and S. Hampshire, "Independent but additive effects of fluorine and nitrogen substitution on properties of a calcium aluminosilicate glass," J. Am. Ceram. Soc., 95 [2] 600-606 (2012).

Á.R. García-Bellés, M. Monzó, A. Barba, C. Clausell, M.J. Pomeroy, A.R. Hanifi, and S. Hampshire, "Factors controlling properties of $\mathrm{Ca}-\mathrm{Mg}, \mathrm{Ca}-\mathrm{Er}, \mathrm{Ca}-\mathrm{Nd}$, or $\mathrm{Ca}-\mathrm{Y}$-modified aluminosilicate glasses containing nitrogen and fluorine," J. Am. Ceram. Soc., 96 [9] 2839-2845 (2013). M.J. Pomeroy, "Preparation and properties of aluminosilicate glasses containing N and F;" pp. 15-22 in Adv. Process. Manuf. Technol. NANOSTRUCTURED Multifunct. Mater. Edited by S. Ohji, T and Singh, M and Mathur. AMER CERAMIC SOC, 735 CERAMIC PLACE, WESTERVILLE, OH 43081-8720 USA, 2015 .

S. Hampshire and M.J. Pomeroy, “Oxynitride glasses,” Int. J. Appl. Ceram. Technol., 5 [2] 155-163 (2008).

R.G. Hill, D. Wood, and M. Thomas, "Trimethylsilylation analysis of the silicate structure of fluoroalumino-silicate glasses and the structural role of fluorine,” J. Mater. Sci., 34 [8] 1767-1774 (1999).

K. Greene, M.J. Pomeroy, S. Hampshire, and R.G. Hill, "Effect of composition on the properties of glasses in the K2O-BaO-MgO-SiO2-A12O3-B2O3-MgF2 system," J. Non. Cryst. Solids, 325 [1-3] 193-205 (2003).

A. Stamboulis, R.G. Hill, and R. V. Law, "Structural characterization of fluorine containing glasses by 
19F, 27Al, 29Si and 31P MAS-NMR spectroscopy,” J. Non. Cryst. Solids, 351 [40] 3289-3295 (2005).

D.N. Coon and T.E. Doyle, "Refractive indices of glasses in the Y-Al-O-N system," J. Non. Cryst. Solids, 108 [2] 180-186 (1989).

42 E.M. Rabinovich, "On the structural role of fluorine in silicate-glasses,” Phys. Chem. Glas., 24 [2] 54-56 (1983) 


\section{List of captions of tables and figures:}

Table I. Effect of nitrogen and fluorine content on physical properties of glasses of cation composition (in equivalent percent) $15 \mathrm{Ca}: 15 \mathrm{Mg}: 55 \mathrm{Si}: 15 \mathrm{Al}$.

Table II. Effect of nitrogen and fluorine content on mechanical properties of glasses of cation composition (in equivalent percent) $15 \mathrm{Ca}: 15 \mathrm{Mg}: 55 \mathrm{Si}: 15 \mathrm{Al}$.

Table III. Effect of nitrogen and fluorine content on thermal and optical properties of glasses of cation composition (in equivalent percent) $15 \mathrm{Ca}: 15 \mathrm{Mg}: 55 \mathrm{Si}: 15 \mathrm{Al}$.

Table IV. Least-squares slopes, intercepts and error band values for effect of nitrogen and fluorine on physical, mechanical, thermal and optical properties.

Fig. 1. Effect of fluorine and nitrogen content on molar volume (MV) for Ca-Mg-Si-Al-O-(N)-(F) glasses. The discrete points represent the experimental data and the lines correspond to the best fit of the data.

Fig. 2. Effect of fluorine and nitrogen content on compactness (C) for Ca-Mg-Si-Al-O-(N)-(F) glasses. The discrete points represent the experimental data and the lines correspond to the best fit of the data.

Fig. 3. Effect of compactness and free volume on Young's modulus ( $\bullet$ ) and microhardness $(\bullet)$ for Ca-Mg-Si-Al-O-(N)-(F) glasses.

Fig. 4. Effect of fluorine or nitrogen substitution level on free volume for Ca-Mg-Si-Al-O-(N)-(F) glasses. Circles correspond to different constant nitrogen contents $(0 \mathrm{~N}, 10 \mathrm{~N}$ and $15 \mathrm{~N})$ with variable fluorine contents; squares correspond to different constant fluorine contents $(0 \mathrm{~F}, 1 \mathrm{~F}, 3 \mathrm{~F}$ and $5 \mathrm{~F})$ with variable nitrogen contents.

Fig. 5. Effect of fluorine and nitrogen content on glass-transition temperature measured by DTA ( $\left.\mathrm{T}_{\mathrm{g}, \mathrm{DTA}}\right)$ for Ca-Mg-Si-Al-O(N)-(F) glasses. The discrete points represent the experimental data and the lines correspond to the best fit of the data.

Fig. 6. Effect of fluorine and nitrogen content on dilatometric-softening temperature ( $\left.\mathrm{T}_{\mathrm{DS}}\right)$ for $\mathrm{Ca}-\mathrm{Mg}-\mathrm{Si}-\mathrm{Al}-\mathrm{O}-(\mathrm{N})-(\mathrm{F})$ glasses. The discrete points represent the experimental data and the lines correspond to the best fit of the data.

Fig. 7. Effect of fluorine and nitrogen content on thermal expansion coefficient $\left(\alpha_{300-600}\right)$ for Ca-Mg-Si-Al-O-(N)-(F) glasses. The discrete points represent the experimental data and the lines correspond to the best fit of the data.

Fig. 8. Effect of fluorine and nitrogen content on refractive index for Ca-Mg-Si-Al-O-(N)-(F) glasses. The discrete points represent the experimental data and the lines correspond to the best fit of the data. 


\section{Table I.}

\begin{tabular}{|c|c|c|c|c|}
\hline $\begin{array}{c}\text { Glass composition } \\
\text { (eq. \%) } \\
\text { Ca:Mg:Si:Al:O:N:F }\end{array}$ & $\begin{array}{l}\text { Bulk } \\
\text { Color }\end{array}$ & $\begin{array}{r}\text { Density } \\
\left(\mathrm{g} / \mathrm{cm}^{3}\right)\end{array}$ & $\begin{array}{c}\text { Molar } \\
\text { volume } \\
\left(\mathrm{cm}^{3} / \mathbf{m o l}\right)\end{array}$ & $\begin{array}{l}\text { Fractional } \\
\text { Compactness }\end{array}$ \\
\hline \multicolumn{5}{|l|}{ ON series } \\
\hline 15:15:55:15:100:0:0 & Colorless & 2.85 & 7.57 & 0.540 \\
\hline $15: 15: 55: 15: 99: 0: 1$ & Colorless & 2.84 & 7.58 & 0.540 \\
\hline $15: 15: 55: 15: 97: 0: 3$ & Colorless & 2.84 & 7.58 & 0.541 \\
\hline $15: 15: 55: 15: 95: 0: 5$ & Colorless & 2.84 & 7.59 & 0.542 \\
\hline \multicolumn{5}{|l|}{$10 \mathrm{~N}$ series } \\
\hline $15: 15: 55: 15: 90: 10: 0$ & Black & 2.89 & 7.47 & 0.550 \\
\hline $15: 15: 55: 15: 89: 10: 1$ & Grey blue & 2.88 & 7.48 & 0.550 \\
\hline $15: 15: 55: 15: 87: 10: 3$ & Grey blue & 2.88 & 7.50 & 0.551 \\
\hline $15: 15: 55: 15: 85: 10: 5$ & Black & 2.88 & 7.49 & 0.552 \\
\hline \multicolumn{5}{|l|}{$15 \mathrm{~N}$ series } \\
\hline $15: 15: 55: 15: 85: 15: 0$ & Dark Grey & 2.90 & 7.45 & 0.553 \\
\hline $15: 15: 55: 15: 84: 15: 1$ & Dark Grey & 2.90 & 7.45 & 0.553 \\
\hline $15: 15: 55: 15: 82: 15: 3$ & Dark Grey & 2.90 & 7.45 & 0.555 \\
\hline $15: 15: 55: 15: 80: 15: 5$ & Dark Grey & 2.90 & 7.46 & 0.557 \\
\hline Experimental error & & \pm 0.01 & \pm 0.01 & \pm 0.001 \\
\hline
\end{tabular}




\section{Table II.}

\begin{tabular}{|c|c|c|c|c|c|}
\hline $\begin{array}{c}\text { Glass composition } \\
\text { (eq. \%) } \\
\text { Ca:Mg:Si:Al:O:N:F }\end{array}$ & $\begin{array}{c}\text { Microhardness } \\
\text { (GPa) }\end{array}$ & $\begin{array}{c}\mathbf{E} \\
(\mathbf{G P a})\end{array}$ & $\begin{array}{c}\mathbf{G} \\
(\mathbf{G P a})\end{array}$ & $\begin{array}{c}\text { B } \\
\text { (GPa) }\end{array}$ & $\begin{array}{l}\text { Poisson's } \\
\text { ratio - v }\end{array}$ \\
\hline \multicolumn{6}{|l|}{$O N$ series } \\
\hline $15: 15: 55: 15: 100: 0: 0$ & 6.55 & 103.4 & 41.3 & 69.3 & 0.25 \\
\hline 15:15:55:15:99:0:1 & 6.61 & 103.1 & 41.2 & 69.2 & 0.25 \\
\hline $15: 15: 55: 15: 97: 0: 3$ & 6.61 & 102.7 & 41.1 & 67.8 & 0.25 \\
\hline $15: 15: 55: 15: 95: 0: 5$ & 6.54 & 103.5 & 41.4 & 69.4 & 0.25 \\
\hline \multicolumn{6}{|l|}{$10 \mathrm{~N}$ series } \\
\hline $15: 15: 55: 15: 90: 10: 0$ & 7.27 & 110.4 & 44.1 & 73.9 & 0.25 \\
\hline $15: 15: 55: 15: 89: 10: 1$ & 7.21 & 110.6 & 44.0 & 75.6 & 0.26 \\
\hline $15: 15: 55: 15: 87: 10: 3$ & 7.28 & 109.3 & 43.4 & 76.1 & 0.26 \\
\hline $15: 15: 55: 15: 85: 10: 5$ & 7.18 & 110.9 & 44.3 & 74.9 & 0.25 \\
\hline \multicolumn{6}{|l|}{$15 \mathrm{~N}$ series } \\
\hline $15: 15: 55: 15: 85: 15: 0$ & 7.86 & 114.5 & 45.7 & 77.5 & 0.25 \\
\hline $15: 15: 55: 15: 84: 15: 1$ & 7.87 & 115.9 & 46.3 & 77.5 & 0.25 \\
\hline $15: 15: 55: 15: 82: 15: 3$ & 7.65 & 114.6 & 45.6 & 78.4 & 0.26 \\
\hline $15: 15: 55: 15: 80: 15: 5$ & 7.78 & 116.1 & 46.4 & 77.6 & 0.25 \\
\hline Experimental error & \pm 0.12 & \pm 1.5 & \pm 1.0 & \pm 1.5 & \pm 0.01 \\
\hline
\end{tabular}




\section{Table III.}

\begin{tabular}{|c|c|c|c|c|c|}
\hline $\begin{array}{c}\text { Glass composition } \\
\text { (eq. \%) } \\
\text { Ca:Mg:Si:Al:O:N:F }\end{array}$ & $\begin{array}{c}\alpha_{300-600} \\
\left({ }^{\circ} \mathbf{C}^{-1}\right) \cdot 10^{6}\end{array}$ & $\begin{array}{c}\mathbf{T}_{\mathrm{g}, \mathrm{DTA}} \\
\left({ }^{\circ} \mathbf{C}\right)\end{array}$ & $\begin{array}{l}\mathbf{T}_{\mathrm{g}, \mathrm{dil}} \\
\left({ }^{\circ} \mathbf{C}\right)\end{array}$ & $\begin{array}{l}\mathbf{T}_{\mathrm{DS}} \\
\left({ }^{\circ} \mathbf{C}\right)\end{array}$ & $\begin{array}{c}\text { Refractive } \\
\text { index }\end{array}$ \\
\hline \multicolumn{6}{|l|}{$0 \mathrm{~N}$ series } \\
\hline $15: 15: 55: 15: 100: 0: 0$ & 9.01 & 759 & 694 & 731 & 1,666 \\
\hline $15: 15: 55: 15: 99: 0: 1$ & 9.21 & 733 & 668 & 714 & 1,661 \\
\hline $15: 15: 55: 15: 97: 0: 3$ & 9.30 & 705 & 640 & 682 & 1,652 \\
\hline 15:15:55:15:95:0:5 & 9.60 & 680 & 615 & 651 & 1,642 \\
\hline \multicolumn{6}{|l|}{$10 \mathrm{~N}$ series } \\
\hline $15: 15: 55: 15: 90: 10: 0$ & 8.59 & 787 & 731 & 773 & 1,702 \\
\hline $15: 15: 55: 15: 89: 10: 1$ & 8.43 & 766 & 700 & 741 & 1,696 \\
\hline $15: 15: 55: 15: 87: 10: 3$ & 8.58 & 734 & 667 & 708 & 1,687 \\
\hline $15: 15: 55: 15: 85: 10: 5$ & 8.66 & 711 & 641 & 690 & 1,675 \\
\hline \multicolumn{6}{|l|}{$15 \mathrm{~N}$ series } \\
\hline $15: 15: 55: 15: 85: 15: 0$ & 8.35 & 810 & 746 & 794 & 1,723 \\
\hline $15: 15: 55: 15: 84: 15: 1$ & 8.21 & 783 & 719 & 757 & 1,711 \\
\hline $15: 15: 55: 15: 82: 15: 3$ & 8.44 & 745 & 682 & 723 & 1,701 \\
\hline $15: 15: 55: 15: 80: 15: 5$ & 9.15 & 720 & 658 & 703 & 1,703 \\
\hline Experimental error & \pm 0.1 & \pm 5 & \pm 5 & \pm 5 & \pm 0.005 \\
\hline
\end{tabular}


Table IV.

\begin{tabular}{|c|c|c|c|c|c|c|}
\hline Property & units & $\begin{array}{c}\text { Intercept } \\
\text { values }\end{array}$ & $\begin{array}{l}\text { N gradient } \\
\left(\begin{array}{lll}\text { eq } \% & N^{-1}\end{array}\right)\end{array}$ & $\begin{array}{l}\text { F gradient } \\
\left(\begin{array}{ll}\text { eq } \% & F^{-1}\end{array}\right)\end{array}$ & $\begin{array}{l}\text { Error } \\
\text { band }\end{array}$ & $\mathbf{R}^{2}$ \\
\hline Molar volume & $\mathrm{cm}^{3} / \mathrm{mol}$ & 7.5689 & -0.0085 & 0.0032 & 0.0082 & 0.9824 \\
\hline Compactness & & 0.5395 & 0.0009 & 0.0006 & 0.0006 & 0.9922 \\
\hline Microhardness & $\mathrm{GPa}$ & 6.58 & 0.079 & -0.014 & 0.101 & 0.9692 \\
\hline $\begin{array}{c}\text { Young's } \\
\text { modulus (E) }\end{array}$ & $\mathrm{GPa}$ & 102.80 & 0.795 & 0.073 & 0.83 & 0.9796 \\
\hline $\begin{array}{c}\text { Share modulus } \\
\text { (G) }\end{array}$ & $\mathrm{GPa}$ & 41.09 & 0.310 & 0.028 & 0.43 & 0.9646 \\
\hline $\begin{array}{l}\text { Compressive } \\
\text { modulus (B) }\end{array}$ & $\mathrm{GPa}$ & 68.83 & 0.596 & 0.063 & 0.76 & 0.9699 \\
\hline $\mathrm{T}_{\mathrm{g}, \mathrm{DTA}}$ & ${ }^{\circ} \mathrm{C}$ & 755.4 & 3.02 & -16.05 & 5.64 & 0.9820 \\
\hline $\mathrm{T}_{\mathrm{g}, \mathrm{dil}}$ & ${ }^{\circ} \mathrm{C}$ & 691.6 & 3.12 & -16.68 & 6.30 & 0.9792 \\
\hline $\mathrm{T}_{\mathrm{DS}}$ & ${ }^{\circ} \mathrm{C}$ & 731.7 & 3.32 & -16.49 & 7.86 & 0.9687 \\
\hline$\alpha_{300-600}$ & ${ }^{\circ} \mathrm{C}^{-1}$ & 9.01 & -0.052 & 0.099 & 0.2152 & 0.8051 \\
\hline Refractive index & & 1.6655 & 0.0036 & -0.0046 & 0.0036 & 0.9836 \\
\hline
\end{tabular}


Fig.1.

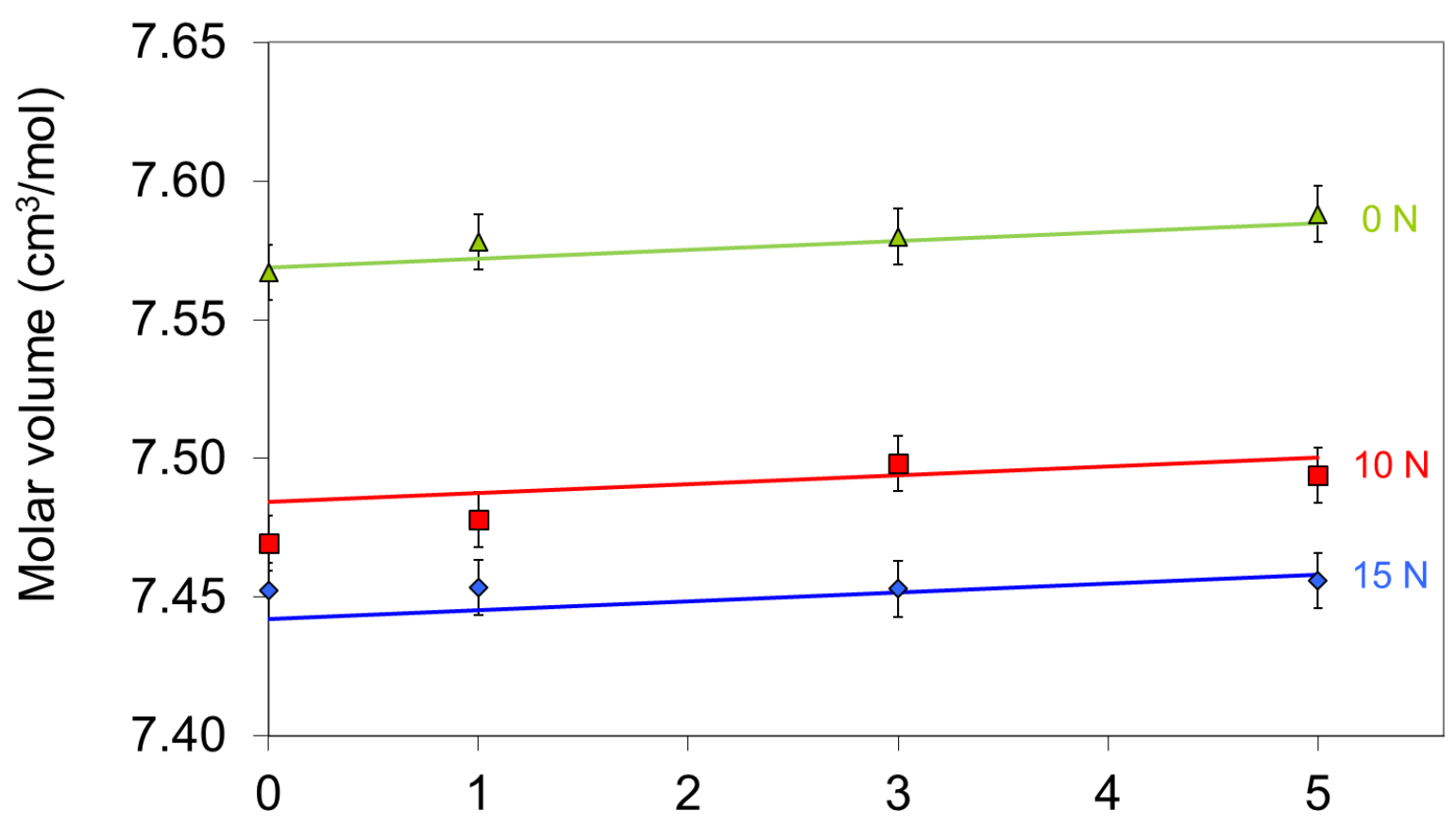

Fluorine (eq\%)

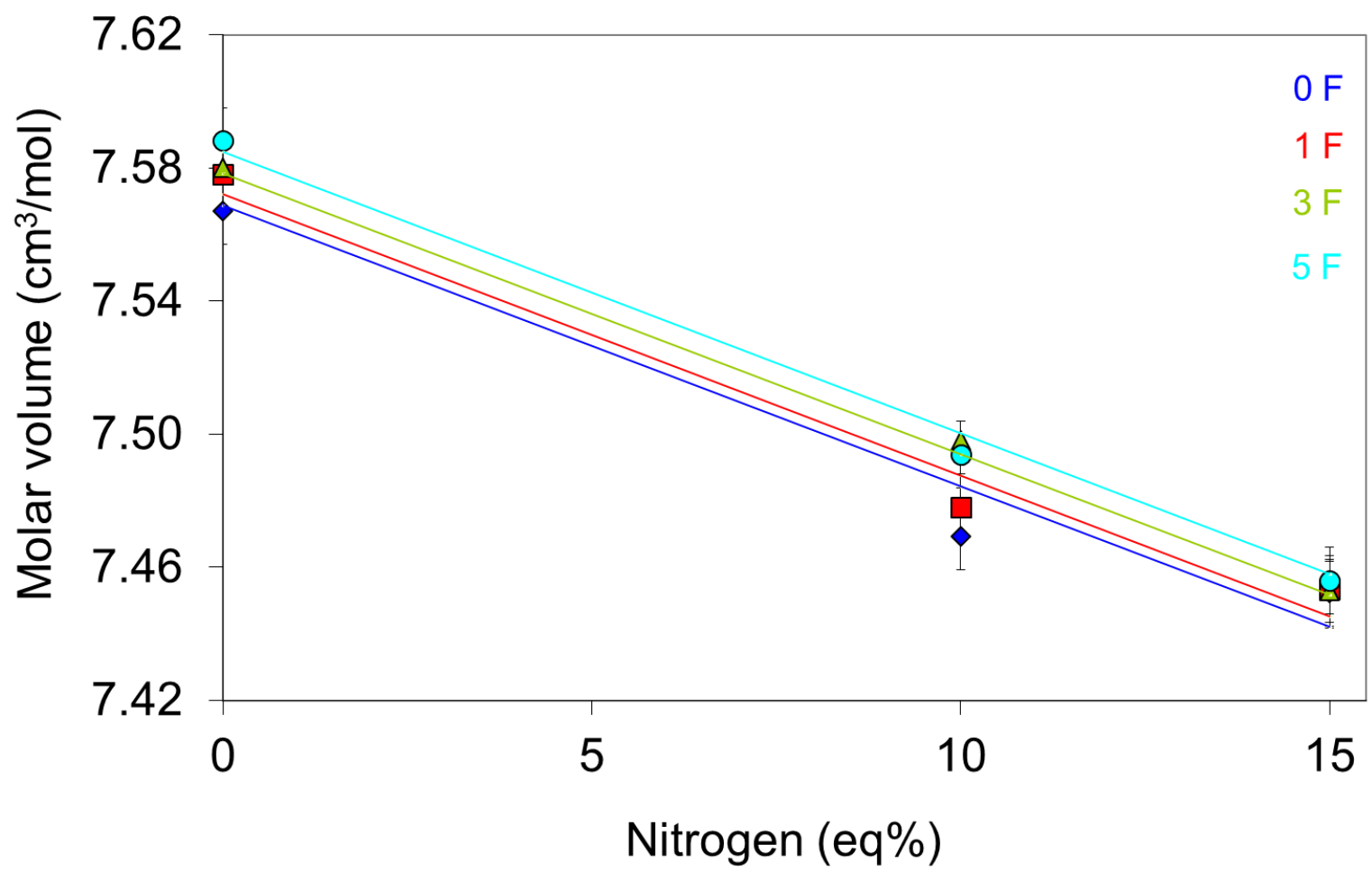


Fig.2.

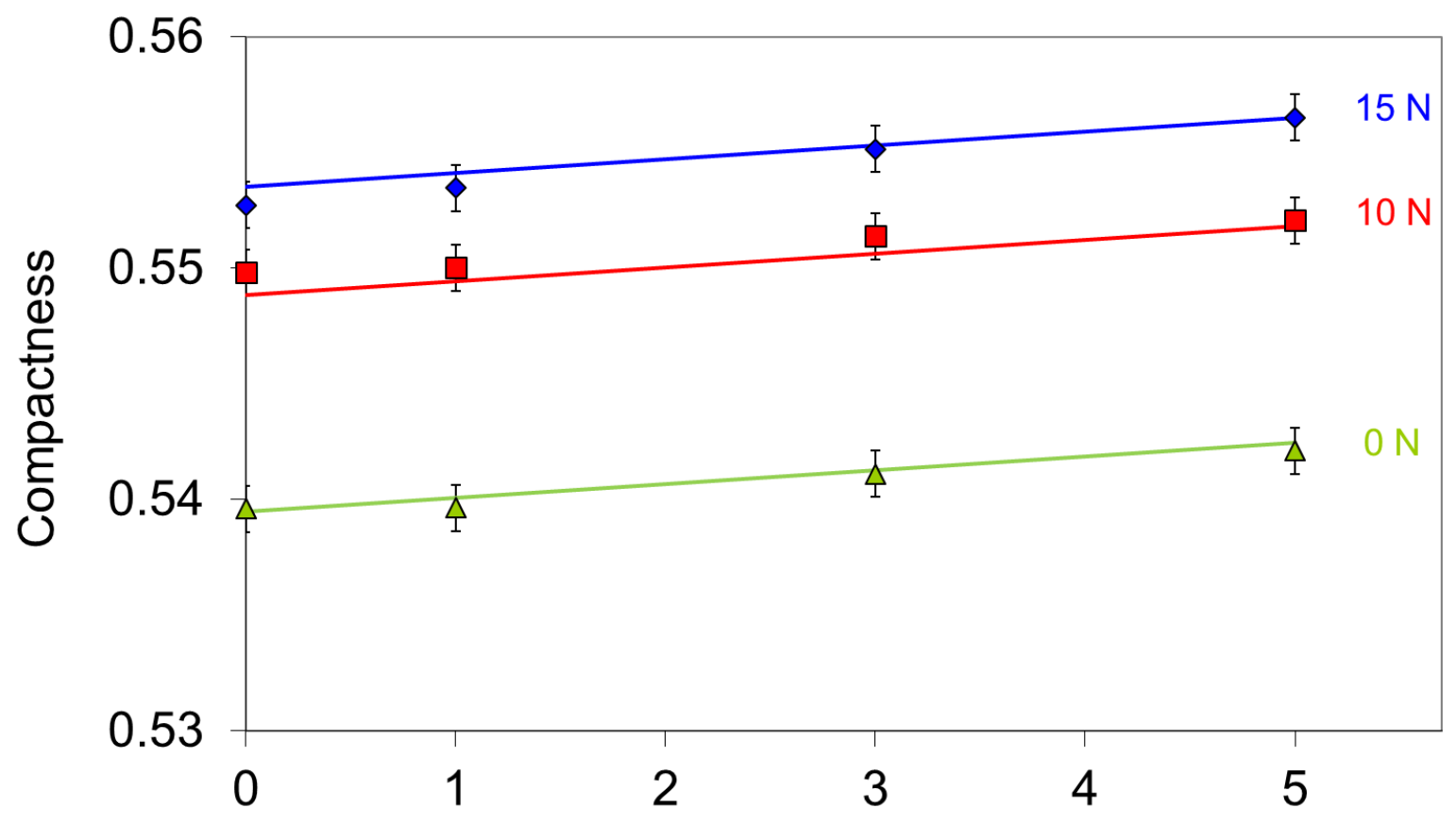

Fluorine (eq\%)

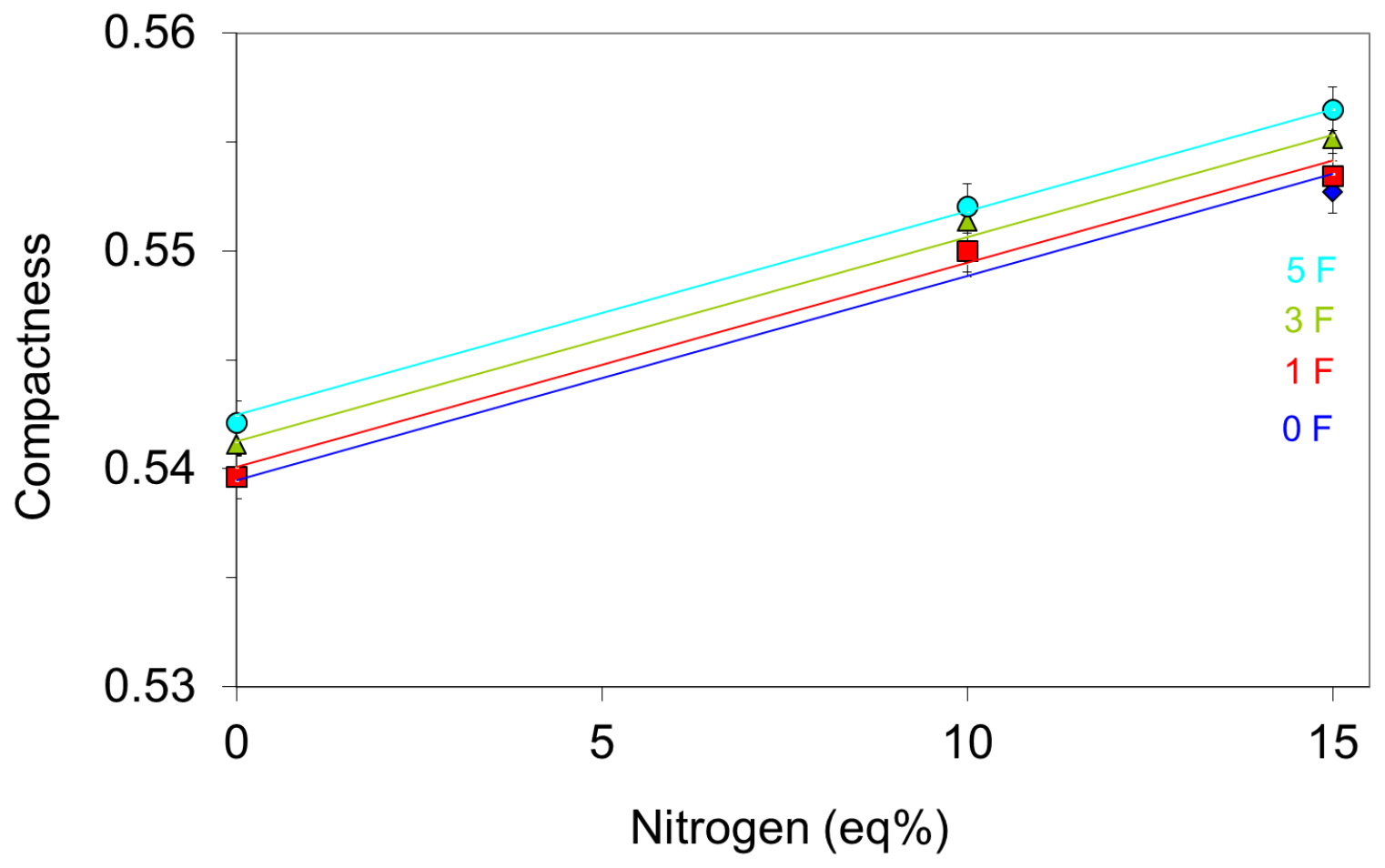


Fig.3.

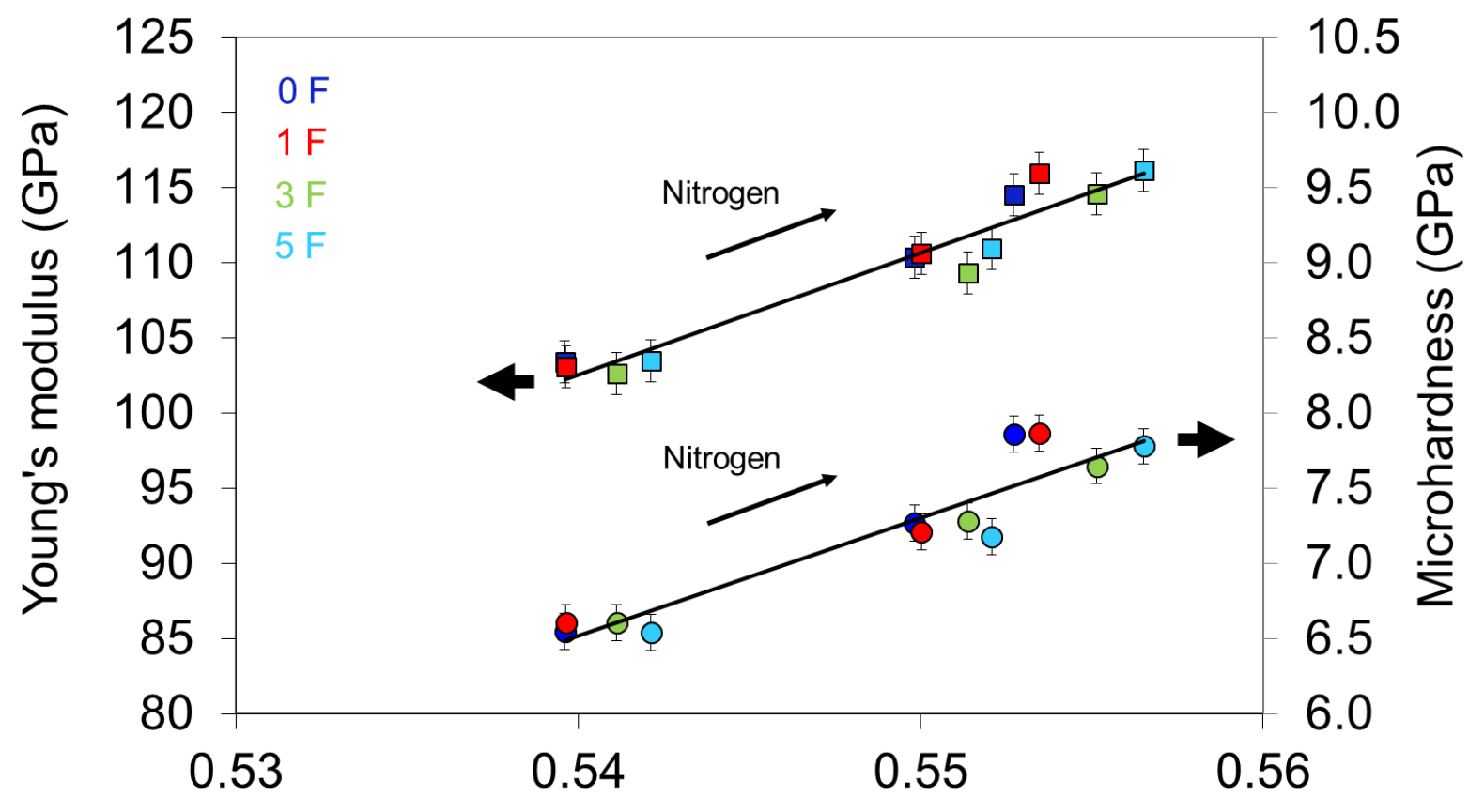

Compactness

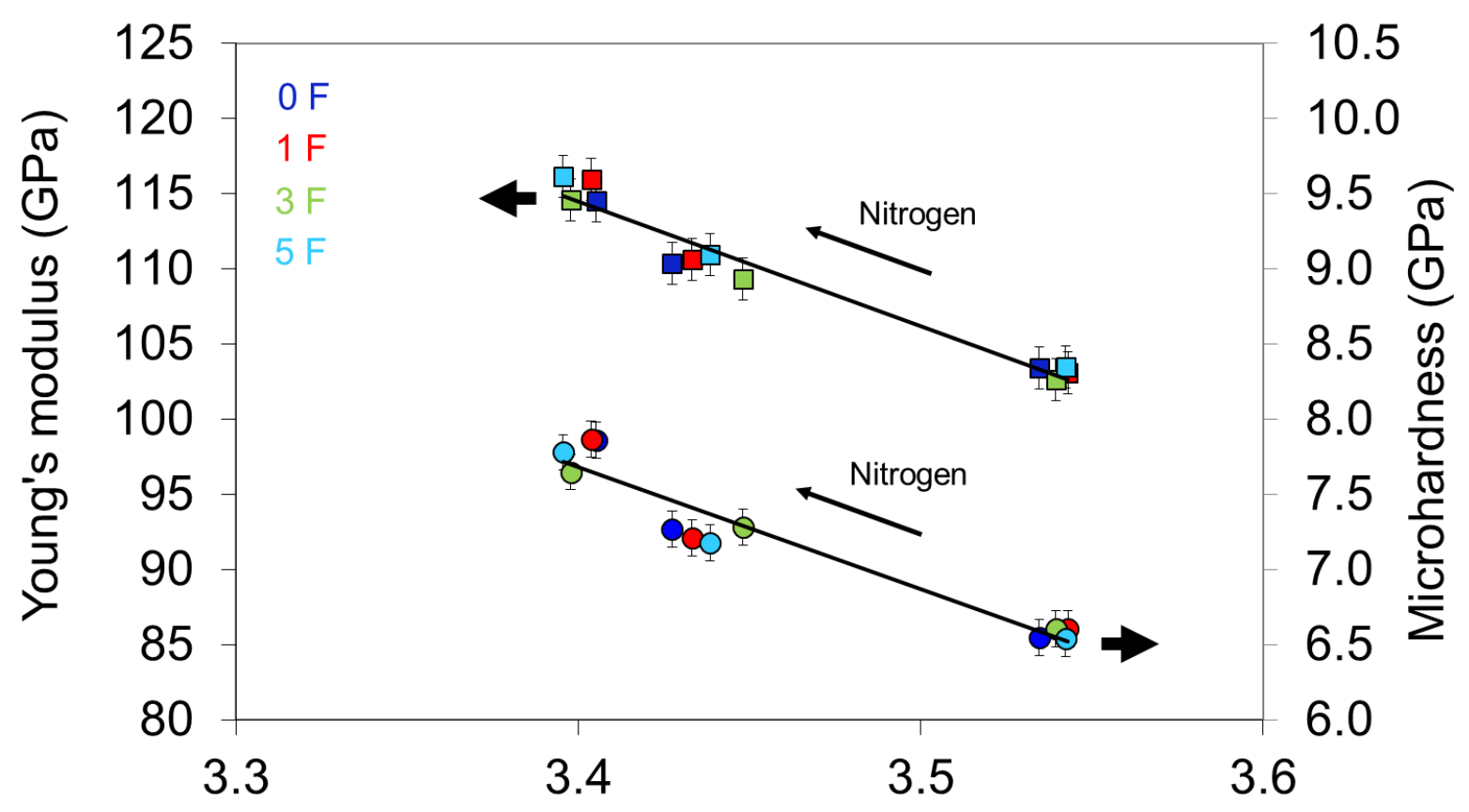

Free volume $\left(\mathrm{cm}^{3} / \mathrm{mol}\right)$ 
Fig.4.

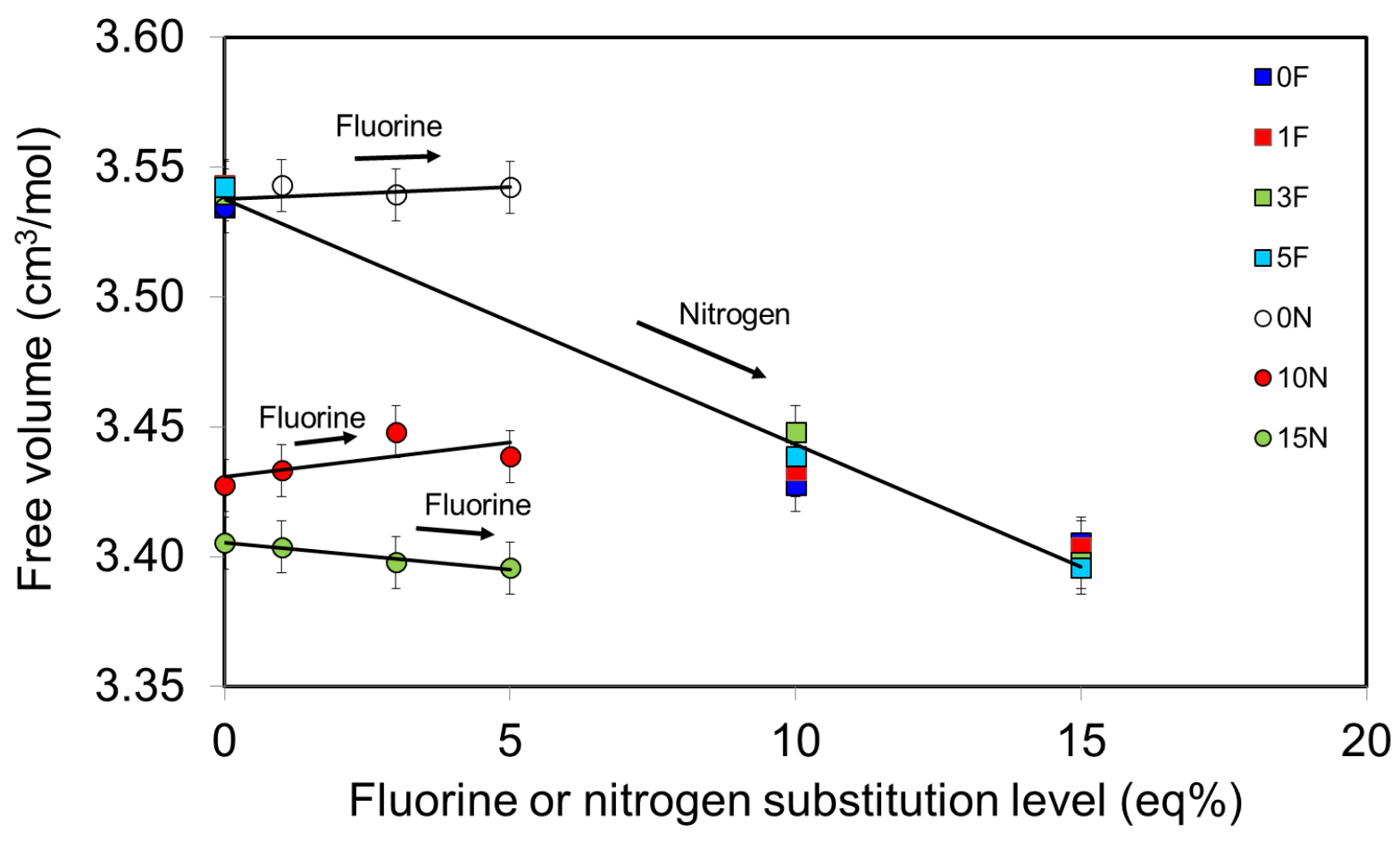


Fig.5.

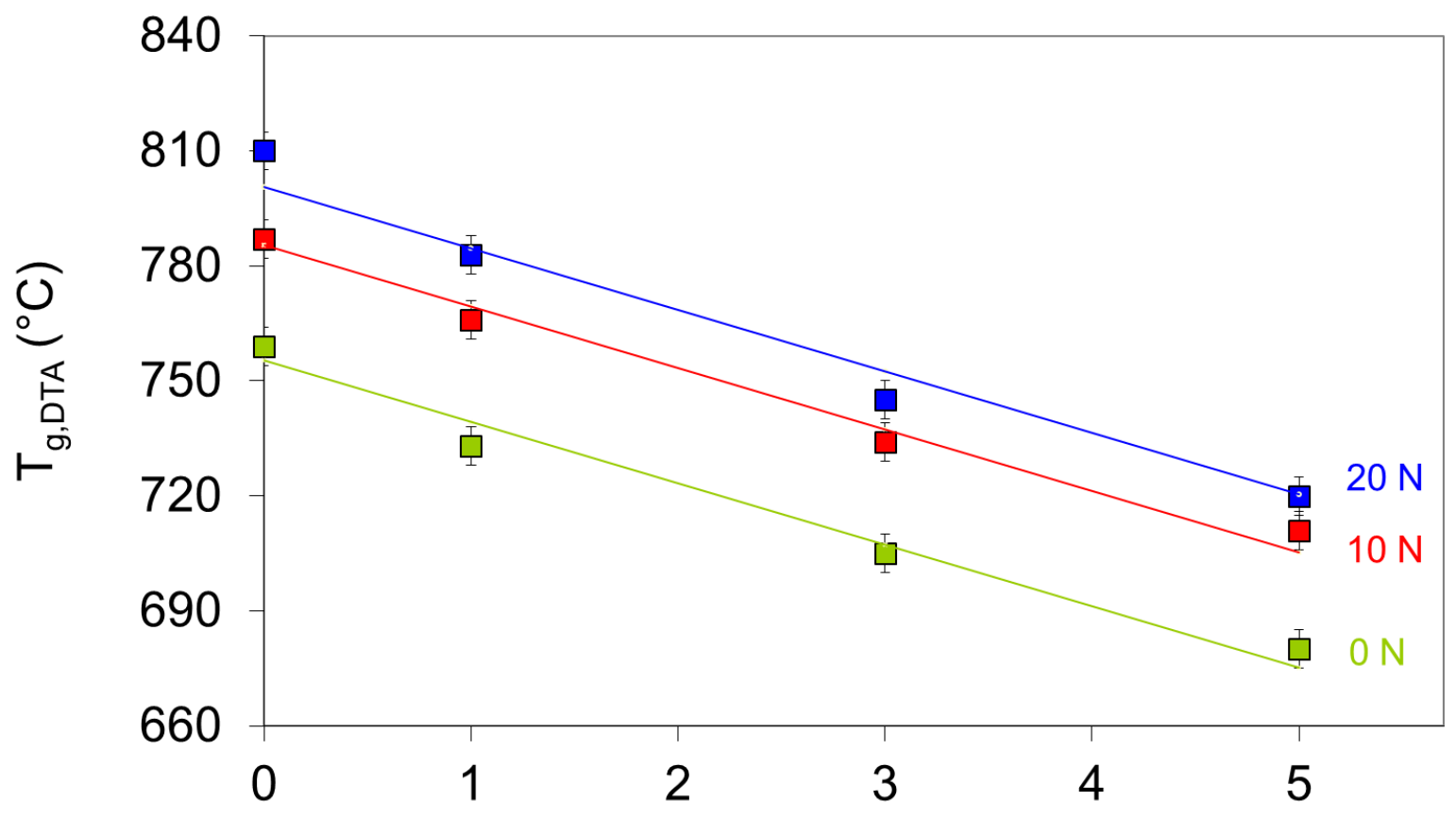

Fluorine (eq\%)

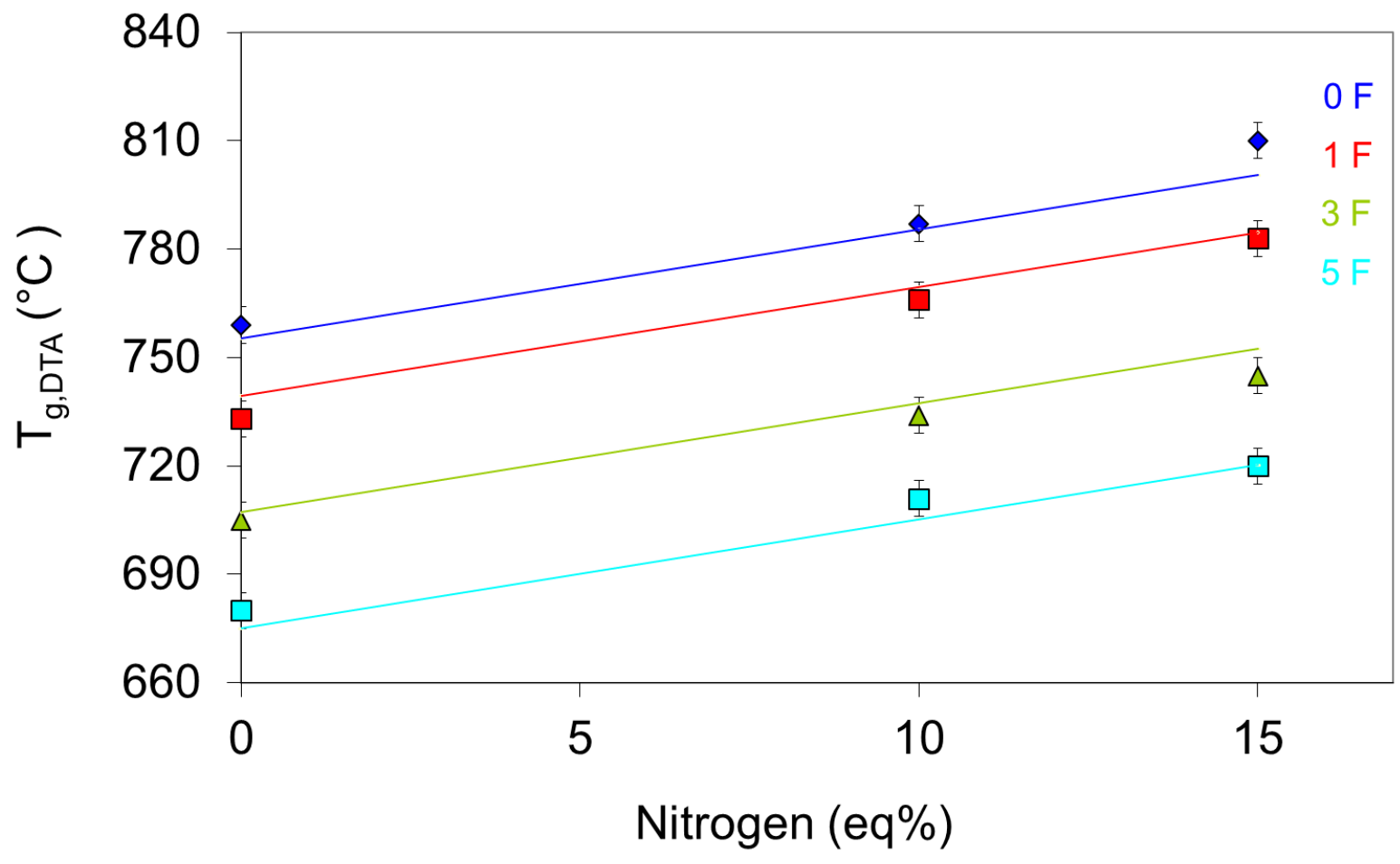


Fig.6.

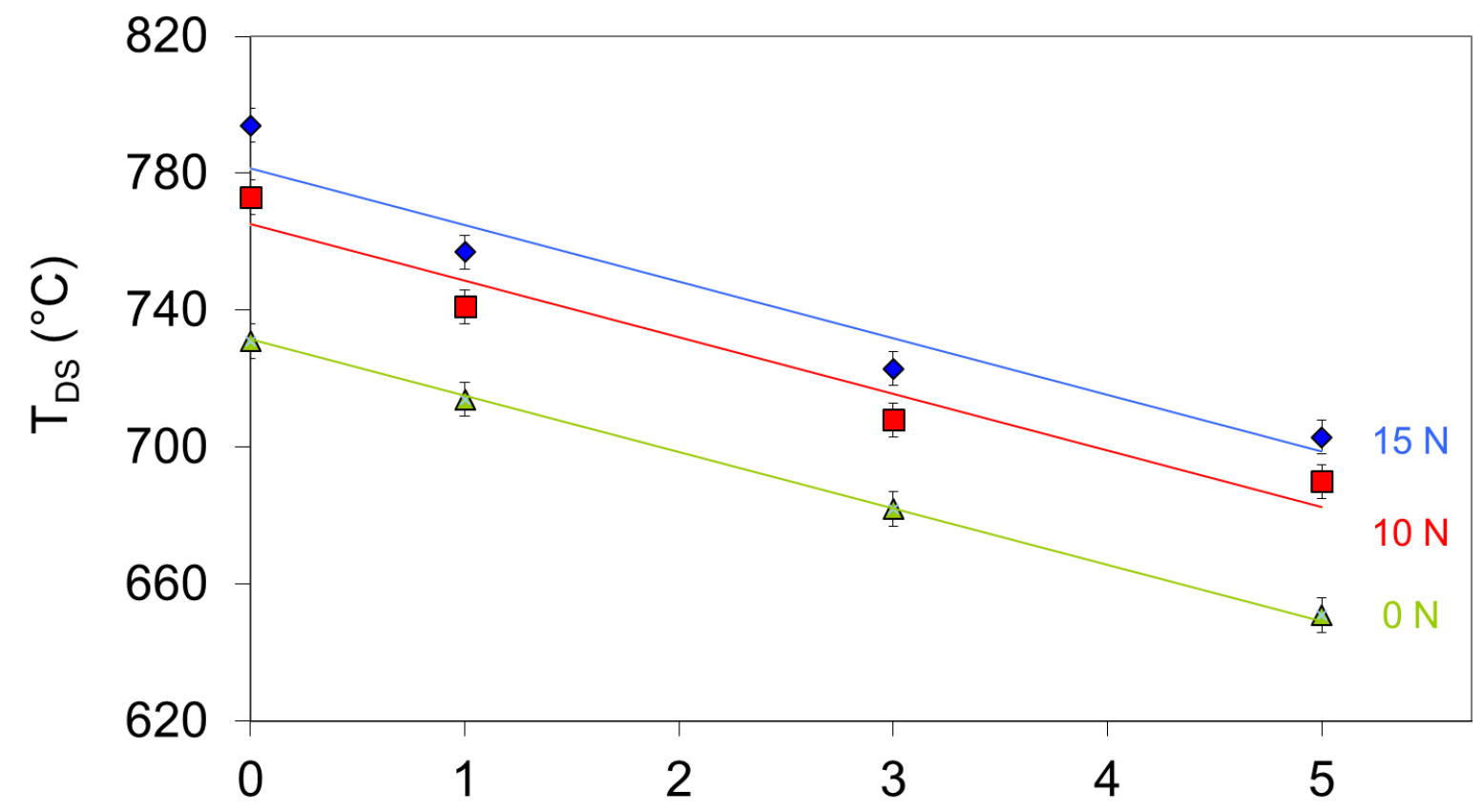

Fluorine (eq $\%$ )

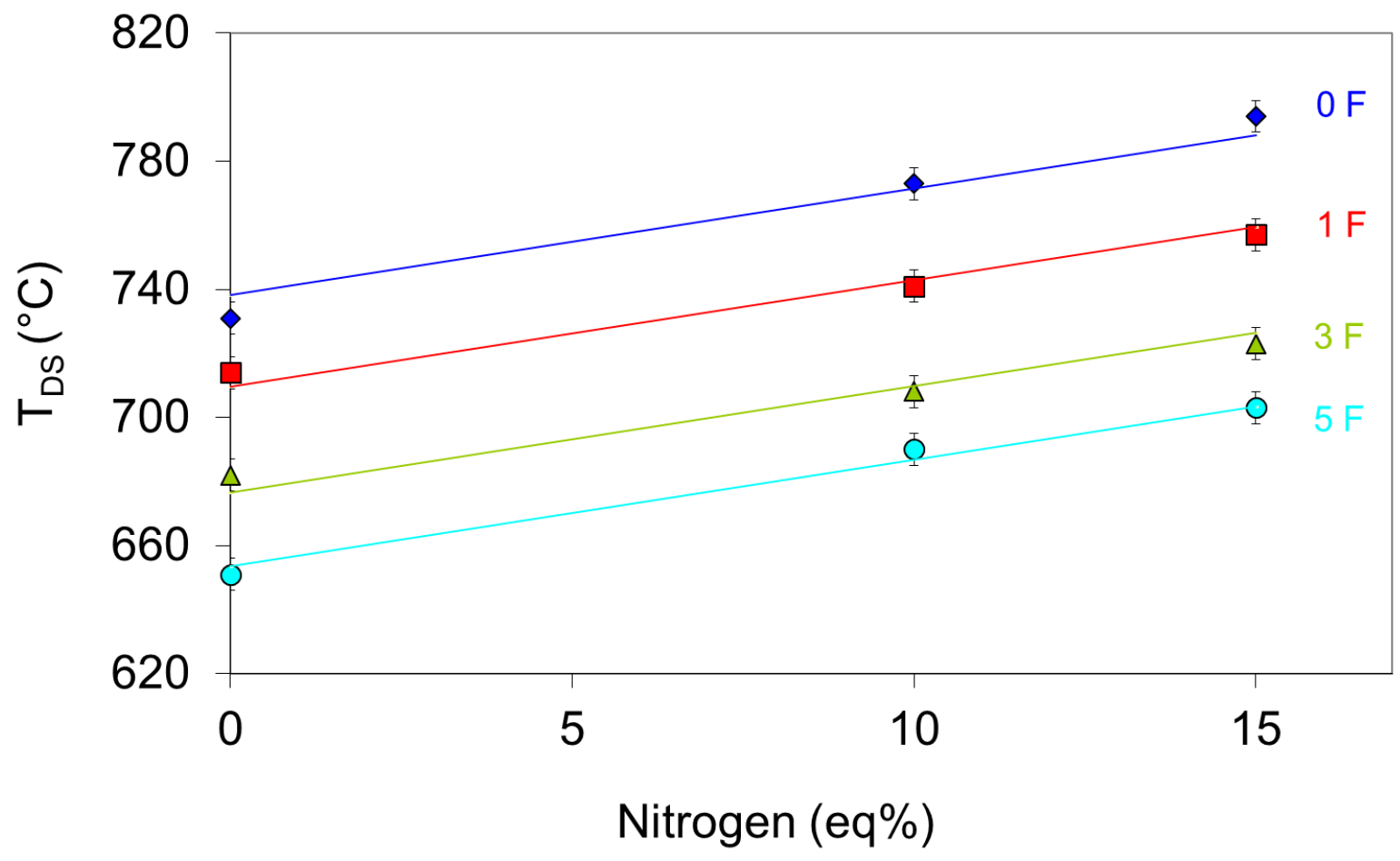


Fig.7.

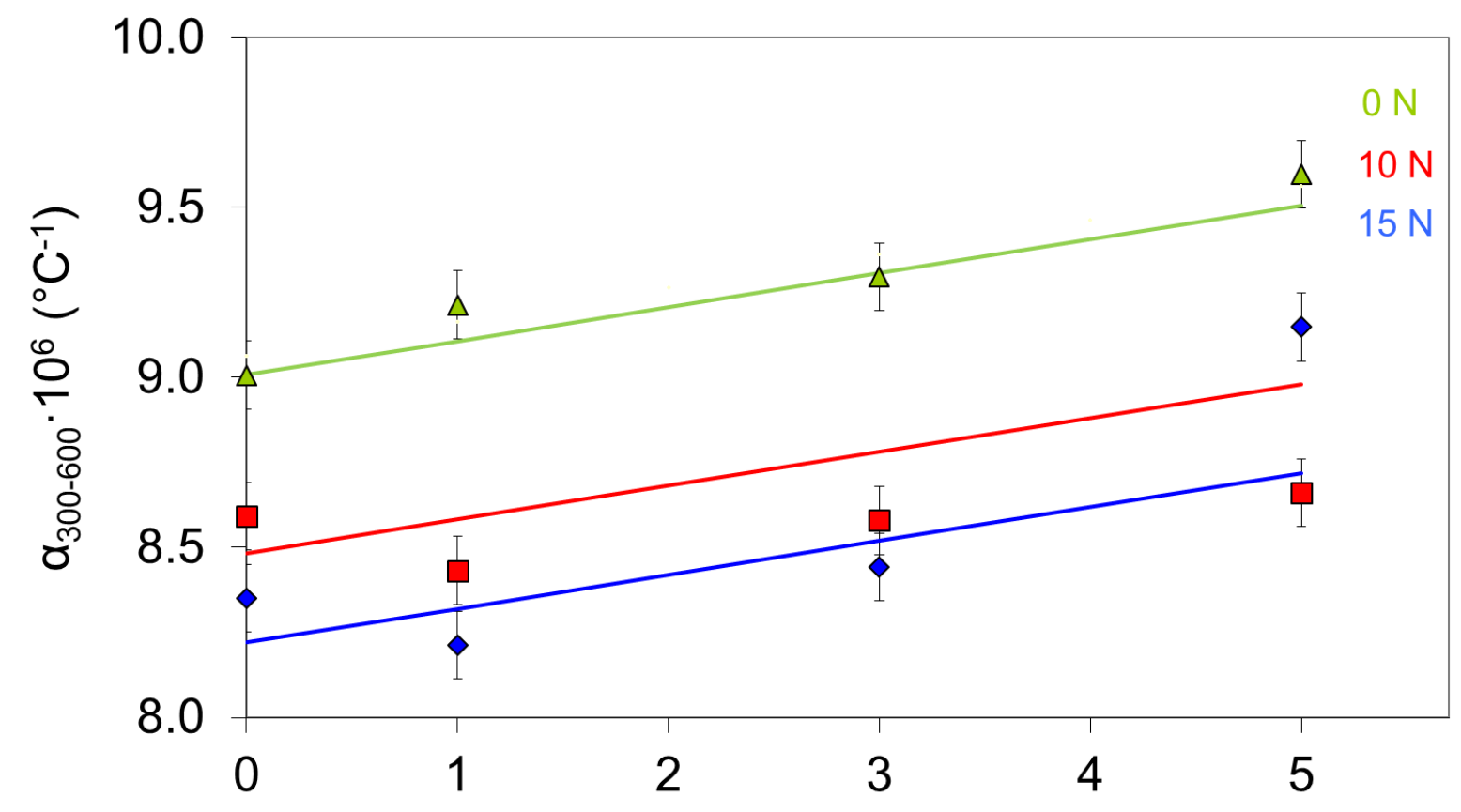

Fluorine (eq\%)

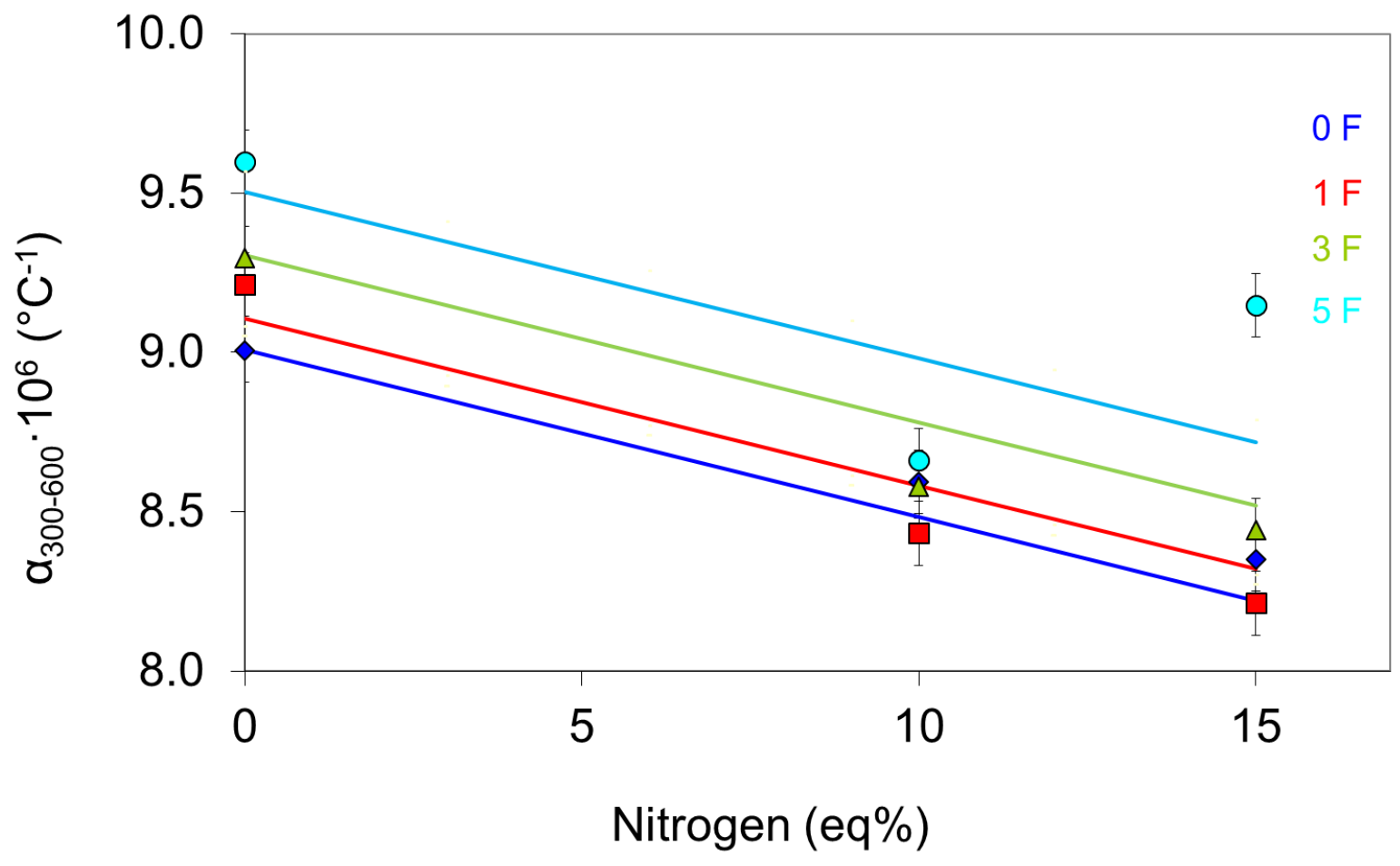


Fig.8.

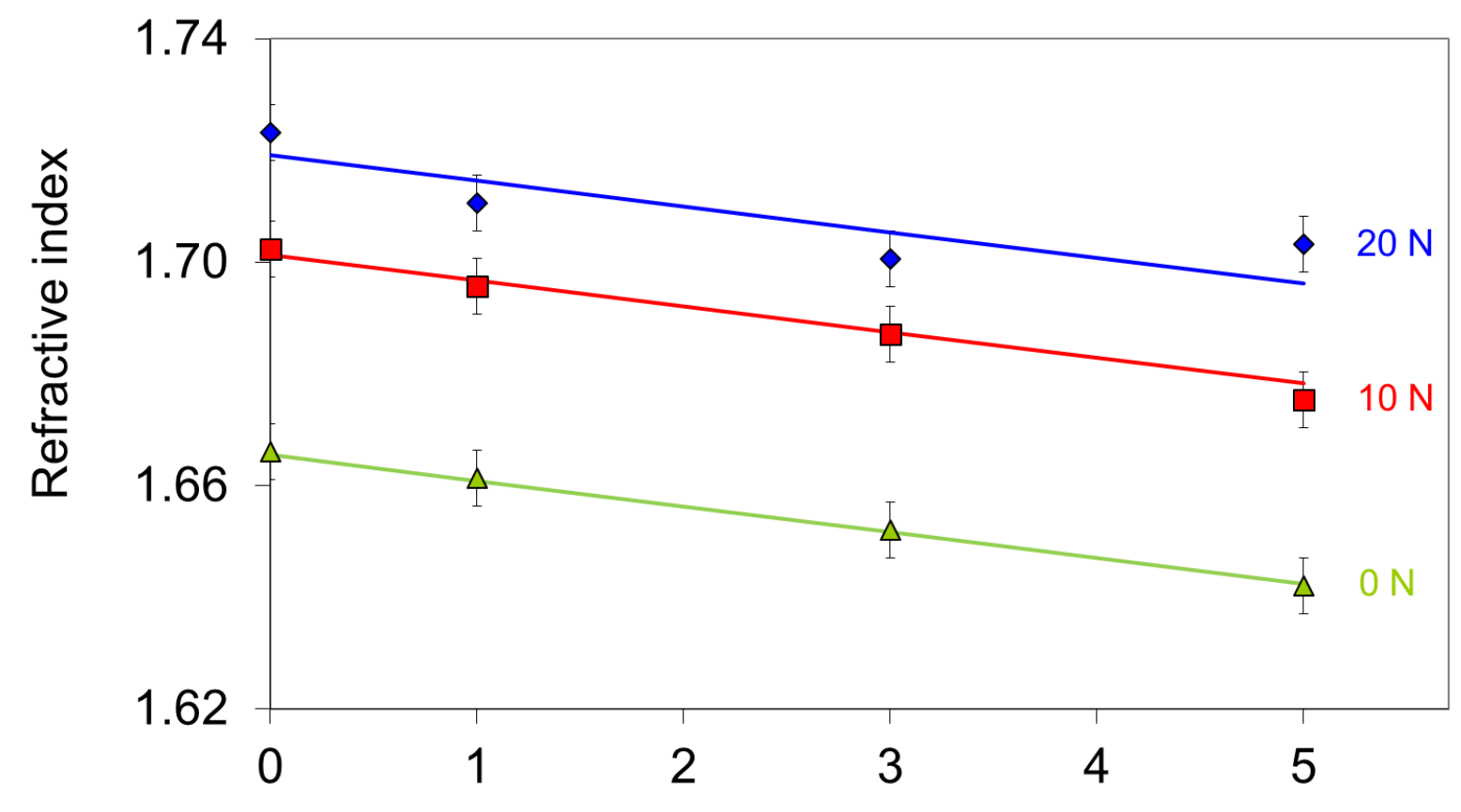

Fluorine (eq\%)

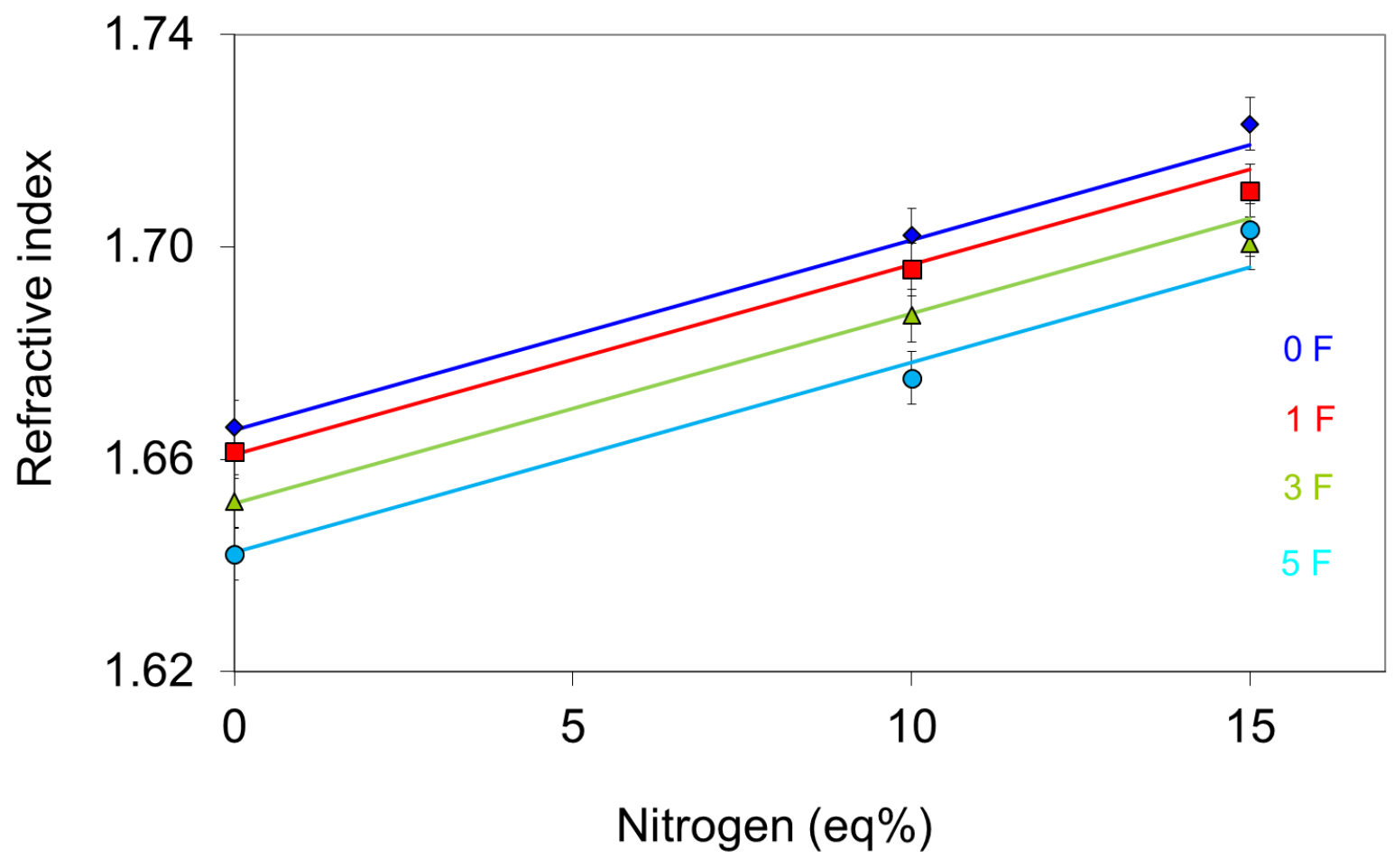

